\title{
WestVirginiaUniversity
}

THE RESEARCH REPOSITORY @ WVU

Graduate Theses, Dissertations, and Problem Reports

2018

\section{Communicated Sex Roles and Gender Identity Gaps.}

\author{
Janelle Vickers
}

Follow this and additional works at: https://researchrepository.wvu.edu/etd

\section{Recommended Citation}

Vickers, Janelle, "Communicated Sex Roles and Gender Identity Gaps." (2018). Graduate Theses, Dissertations, and Problem Reports. 8211.

https://researchrepository.wvu.edu/etd/8211

This Thesis is protected by copyright and/or related rights. It has been brought to you by the The Research Repository @ WVU with permission from the rights-holder(s). You are free to use this Thesis in any way that is permitted by the copyright and related rights legislation that applies to your use. For other uses you must obtain permission from the rights-holder(s) directly, unless additional rights are indicated by a Creative Commons license in the record and/ or on the work itself. This Thesis has been accepted for inclusion in WVU Graduate Theses, Dissertations, and Problem Reports collection by an authorized administrator of The Research Repository @ WVU. For more information, please contact researchrepository@mail.wvu.edu. 
Communicated Sex Roles and Gender Identity Gaps

Janelle Vickers

\author{
Thesis submitted \\ to the Eberly College of Arts and Sciences \\ at West Virginia University \\ in partial fulfillment of the requirements \\ for the degree of \\ Master of Arts in \\ Communication Theory and Research
}

Christine E. Rittenour Ph.D., Chair

Megan R. Dillow Ph.D.

Matthew M. Martin Ph.D.

Department of Communication

Morgantown, West Virginia

2018

Keywords: Identity, Communication Theory of Identity, Gender, Sex Roles

Copyright 2018 Janelle Vickers 


\section{ABSTRACT \\ Communicated Sex Roles and Gender Identity Gaps \\ Janelle Vickers}

Using Communication Theory of Identity (CTI) and the Bem Sex Role Index (BSRI), this study addresses the potential impact of societally-created, gendered expectations on the satisfaction of emerging adults. Two hundred twenty-nine undergraduates at a large mid-Atlantic university participated in the study by completing an online survey assessing gender, identity, and a relationship with a close other of their choosing. Results replicate previous research using CTI, which suggests that identity gaps relating to gender are dissatisfying. Specifically, gaps at the personal-enacted, personal-relational, and the newly-created personal-personal levels were negatively related to participant satisfaction, and personal-relational gaps were negatively correlated with relational satisfaction. Additionally, self-efficacy influenced the magnitude of these trends. Results include factor analyses and the development of a new CTI measure which, like the previously-established CTI measures, correlated to participants' reported levels of satisfaction. Results also suggest a need to implement the BSRI in modern research. This study provides support for the importance of understanding the impact gender identity and sex roles can have on the relationships and happiness of emerging adults. 


\section{ACKNOWLEDGEMENTS}

I would be remiss if I didn't acknowledge the amazing team of faculty members who made the completion of this thesis possible.

Firstly, to Dr. Matthew Martin-while crafting this project, I needed an expert data analyst, someone who was familiar with measurements I employed, and a person who could take a unique perspective toward my topic of interest. Amazingly, you were all of the above. Thank you for all of the valuable guidance you provided this year.

To Dr. Megan Dillow_since my days as an undergraduate in your classes, I have admired your passion for and commitment to communication research. I could think of no one better to help guide this thesis through the process of survey design, and was was honored when you agreed to be on my committee - even though I know the topic wasn't exactly your "jam!" I valued all of your commentary, suggestions, and thoughtful line edits during my writing and research process more than you know.

Finally, to Dr. Christine Rittenour-without your unparalleled warmth, support, and knowledge, this project would have never made it off the ground. In fact, I would never have taken a chance on the Masters program at all without your loving mentorship. Thank you endlessly for the many morning meetings, for your hours of help with data analysis, and for never doubting my abilities, even when I doubted myself. 


\section{Table of Contents}

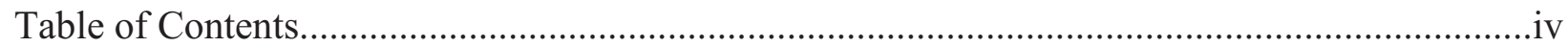

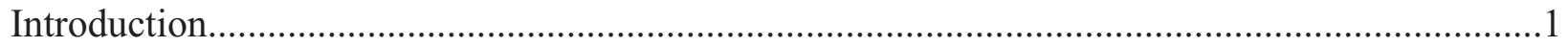

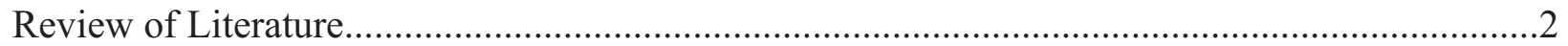

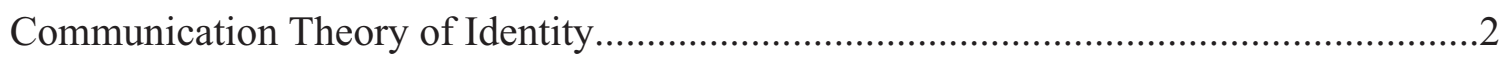

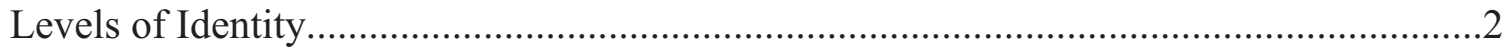

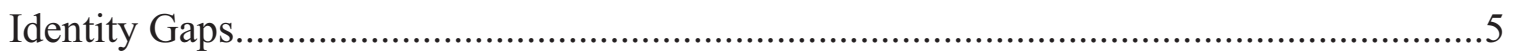

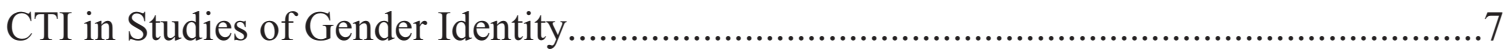

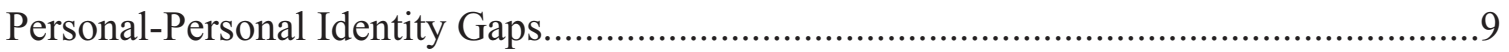

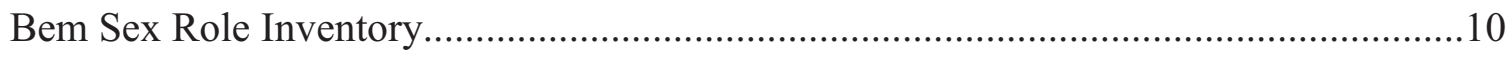

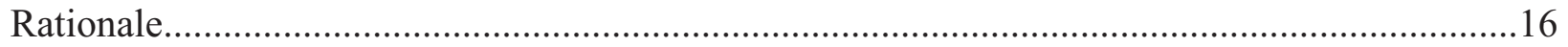

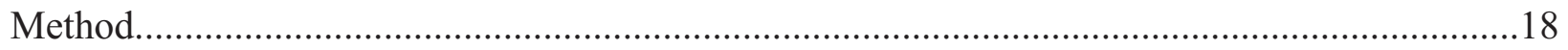

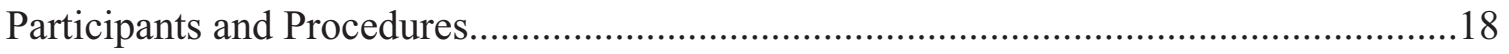

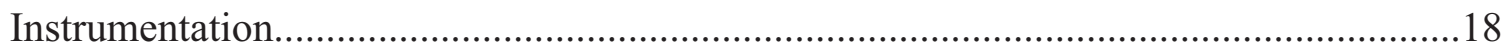

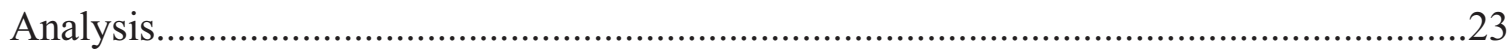

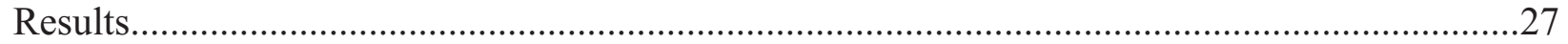

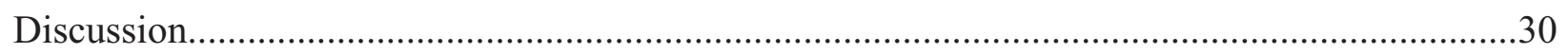

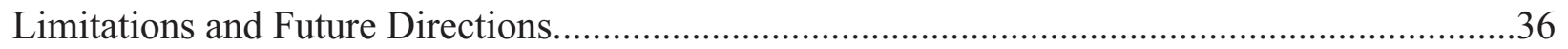

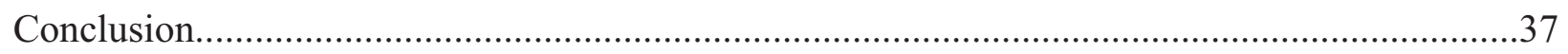

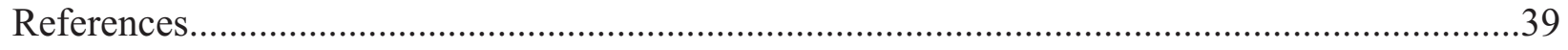

Appendices

Appendix A: Results

Table 1. 


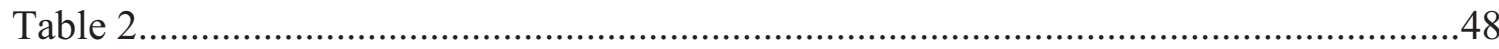

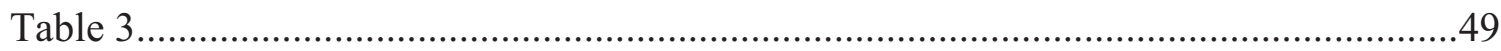

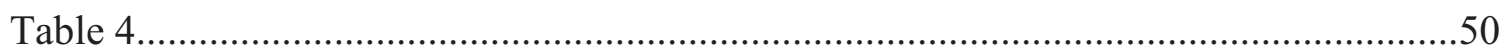

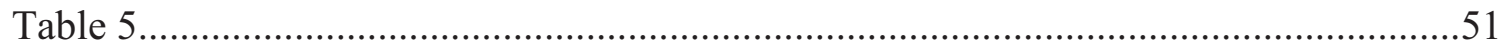

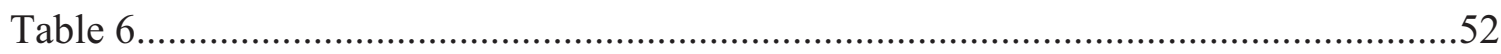

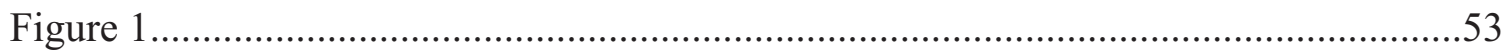

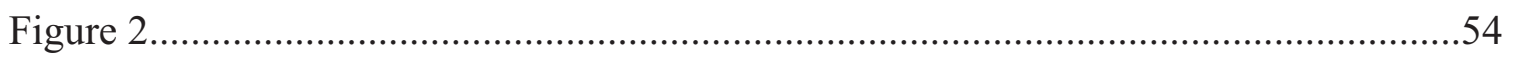

Appendix B: Recruitment Materials

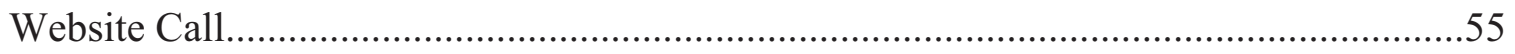

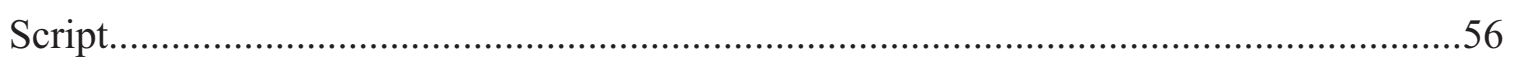

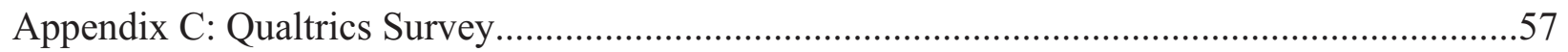




\section{CHAPTER ONE}

\section{Introduction}

Simone de Beauvoir discussed the prospect of a societally-constructed view of womanhood in her 1952 book The Second Sex, a sentiment later echoed in Monique Wittig's essay "One is Not Born a Woman." These feminist scholars assert that it is society and culturenot biology or psychology — that determines the definition of and ascribes acceptable traits to the abstract definition of womanhood. These foundational feminist treatises led to the 1990 publication of Judith Butler's Gender Trouble: Feminism and the Subversion of Identity, wherein the author declared that all gender is performative, enacted publicly, and produced and reproduced to fit into a societally-generated expectation of what gender is meant to be.

While an understanding of the navigation between gender expectations and internal gender identity is common in feminist theory, communication theory has also examined the ways in which gender is moderated and presented. Since the dawn of the $21^{\text {st }}$ century, more gender and feminist scholars are finding theoretical knowledge of use in their exploration of the ways in which genders, sexualities, and identities are communicated (Berryman-Fink, Bing, Cameron, Sheldon, \& Taylor, 2008).

In light of modern, updated views on gender fluidity, as well as the complexities of today's gendered norms and expectations, this thesis proposes six hypotheses and a research question driven by an argument that the fulfillment of gendered expectations leads to higher life satisfaction $(\mathrm{H} 1 ; \mathrm{H} 5)$ and higher relational satisfaction $(\mathrm{H} 3)$, and these relationships are moderated by an individual's efficaciousness (H2; H4). Further, it is argued that highly feminine participants would be less satisfied, but the possession of an androgynous gender identity increases an individual's life satisfaction (H6). Finally, the relationship between gender salience, 
identity, and satisfaction was explored (RQ1). These arguments follow within discussions of Communication Theory of Identity and its subsumed identity gaps, and Bem's Sex Role Inventory.

\section{Review of Literature}

\section{Communication Theory of Identity}

The Communication Theory of Identity (CTI) originated as a way to explain the influence differing cultures and societies have on the conceptualization of an individual's sense of self (Hecht, Warren, Jung, \& Krieger, 2005). CTI views "social behavior, itself, as an aspect of self - the enacted identity," and posits that "a person's sense of self is part of his or her social behavior, and the sense of self emerges and is defined and redefined in social interaction" (Hecht et al, 2005, pp. 260), and thus, is a theoretical framework ideal for the current exploration. What follows is a description of the levels, along with examples from previous literature, in order to illuminate their distinctiveness.

\section{Levels of Identity}

In CTI, Hecht proposes the existence of four levels of identity: personal, relational, enacted, and communal. Each layer is representative of a different aspect of an individual's selfhood. The layers of identity do not exist in isolation from each other; instead, the layers are "interpenetrated" and work together to form the individual's overall identity, and cannot be examined as separate entities (Hecht et al., 2005).

The first layer, known as the personal layer, involves an individual's "self-concept, selfimage, self-cognitions, feelings about self, and/or spiritual sense of well-being," and the way that individual defines him or herself (Hecht et al., 2005, pp. 263). The personal layer of CTI is similar to the personal identity tucked within the related and prominently employed Social 
Identity Theory (Tajfel \& Turner, 1986) in that it is centered around individualized characteristics and behaviors of the individual, but is dissimilar to SIT in that this first CTI layer remains within the individual's thoughts about him or herself, and does not directly employ the outsider's perspectives of his or her uniqueness, as is true in SIT.

The second layer, known as the enactment layer, deals with the ways in which an individual's identity is communicated or performed publicly. The conceptualization of the enactment layer is very closely related to Judith Butler's idea of gender performativity (1990), wherein the identity of an individual is created and maintained through interactions with others. The distinction and interplay between these first two layers is effectively applied to the behaviors of individuals' within their romantic relationships. The more insular, or private couples in the Kennedy-Lightsey, Martin, LaBelle, and Weber (2015) piece reported that the ways in which their true dyadic relationship differed from the ways the couple enacted their relationship publicly. This evidence lends support to the idea of a noticeable difference between a privatelyheld self or unitary identity and the identity publicly enacted before a real or imagined audience.

At the relational layer, the third in CTI, identity is produced and maintained jointly through communication that occurs within relationships and directly involves both interactants. Hecht et al. (2005) separated the relational level into three sub-levels. Firstly, an individual's sense of self is created and maintained by the views of others; secondly, an individual may create a sense of self revolving around connections to others, such as a romantic partner, child, or friend. The third sub-layer of relational identity occurs when a relational unit, such as a married couple, develops a joint identity. Relational identity, as conceptualized by CTI, can be utilized to explore the ways in which individuals with unique identities at the personal level manage and maintain their relationships, as in the case of unconventionally-single Japanese women who 
struggle to maintain both dating and family relationships while possessing a societally-divergent personal identity (Maeda \& Hecht, 2012).

The fourth and final layer of identity develops based on an individual's group memberships or group characteristics and is known as a communal identity. A particular subpopulation or community can hold expectations of acceptable behavior for its members, or expectations for members of other societies and communities. There is no limit or scope placed on the size of the potential group of study as conceptualized in CTI; a communal identity may develop around groups both large and small. As with the relational level, studies implementing the concept of the communal layer from CTI are not uncommon; previous studies include a content analysis from Northern Exposure, a television show that centers on the experiences of a Jewish man as a representative of his religious and ethnic community (Hecht et al., 2002). The show — and the content analysis — focuses on the main character, Joel, and his interactions and identification with his community at large. Both when Joel finds support for his ethnic and religious identity, and when he feels distanciated because of it, he works to discover and secure his place within the town's communal identity.

While Hecht conceptualized four distinct identity layers in his initial theorizing, subsequent research reveals that individuals may have multiple distinct identities that exist simultaneously at a single layer. Adopted children who have contact with both their birth and adopted families can develop two separate and distinct relationship identities: one that exists when they are with their birth families, and another when they spend time with their adopted families (Colaner, Halliwell, \& Guignon, 2014). Kam and Hecht (2009) also uncovered these within-layer differentiations in their study of adult grandchild and grandparent relationships; with their peer groups, young adults may enact more leadership behaviors and qualities, while 
with their extended families, the same individuals could perceive themselves to be more follower-like. Both conceptualizations of and interactions with the different relationships of the respective sample populations reflect how identity levels are not universal for every person in every situation; one individual may shift or alter their identity dependent upon his or her surroundings. Similarly, this thesis addresses the potential for more gaps that did not exist in Hecht's initial proposal of a four-leveled system of identity.

As theorized by Hecht — and as shown in the above-mentioned studies — a large part of the management of the different layers of identity is tied to an individual's ability to effectively navigate the world and present themselves to others in a satisfactory way. Thus, is is likely that the more effective, or efficacious, an individual is at enacting these management behaviors, the easier it would be to manage the different identities created and performed publically. Personally held belief in an individual's ability to affect change or maintain a life state, or complete a behavior, is known as self-efficacy (Sherer et al., 1982). Higher levels of self-efficacy have been linked to increased problem-solving, strategizing, and planning in previous studies ( $\mathrm{Li}$, Eschenauer, \& Persaud, 2018; Wilson, Sheehan, Palk, \& Watson, 2016). Therefore, it is likely that a highly efficacious individual would be more able to successfully manage the complex interactions of different identities and maintain similarity between the different layers of identity when compared to a non-efficacious individual.

While such consonance among the layers is common and satisfying, the complexity of human interaction and societal expectation leads to dissonance among and between these layers of identity; these dissonant experiences are called identity gaps.

\section{Identity Gaps}

CTI argues that an individual's sense of self is, in part, developed via the individual's 
impressions of the way others perceive him or her. These perceptions typically involve how well the individual fits into or conforms with a particular society or culture's prescribed view of norms for behavior. Hecht's conceptualization of the creation and enactment of identity exists in a parallel to Butler's assertion that gender identity is publicly enacted by an individual in order to conform with societal gender expectations. Both Hecht and Butler argue that the pressure to conform or maintain an acceptable social presence can cause an individual to develop a dichotomous view of themselves, and the development of a private identity and a public persona. This allows the individual to enact — or, to quote Judith Butler, perform — culturally acceptable behaviors in their close relationships and communities, despite possessing a personally held or developed identity that differs.

This dichotomous development of a sense of self, wherein any one of the identities held by an individual do not align with one or more other identity layers, is defined by Hecht et al (2005) as an identity gap. Theoretically, gaps can occur between any of the four layers, leading to 11 possible identity gap permutations (Jung \& Hecht, 2004); therefore, the development of identity gaps is hardly a unique experience. While gaps are possible at numerous points, certain gaps have appeared and been studied more commonly than any other in the literature. Two notable gaps are the personal-enacted and personal-relational identity gaps. Personal-enacted identity gaps concern the discrepancy of the ways in which an individual self-identifies and how his or her identity is communicated to others, while personal-relational identity gaps occur when others' perceptions of an individual — including their shared and potentially co-created identityare different than the individual's own self-perceptions (Jung \& Hecht, 2004). In the current study, these gaps are hypothesized to manifest when individuals' personally held sex-role identification does not align with the behaviors they enact, or the ways others view them. 
CTI and the theory's conceptualization of identity gaps are frequently used (and useful) in studies targeting the experiences of marginalized and minority group members. Wadsworth, Hecht, and Jung (2008) used CTI to examine the identity gap experiences within a sample population of international students studying at universities in the United States. The researchers discovered that within their sample population, foreign students were most likely to experience gaps at the personal-enacted level, wherein an individual felt as though the persona he or she created in order to "fit in" at an American university was not true to who he or she was. In another study of immigrants in the United States, gaps were uncovered at multiple combinations of identity levels, including personal-enacted, personal-relational, enacted-relational, communalrelational, personal-communal, and enacted-communal (Urban \& Orbe, 2010). Husbands and wives with lower self-esteem were more likely to develop personal-enacted identity gaps, wherein their lower-self-confidence led to feelings of doubt about their performances in public spaces or conversations (Kennedy-Lightsey, Martin, LaBelle, \& Weber, 2015). This development of a gap between the personally held identity and the shared relationship identity could coincide with a decrease in relationship satisfaction.

While the gaps between layers are commonly studied, it is also possible for individuals to develop identity gaps within a single identity layer. In a study of adult adoptees, Colaner, Halliwell, and Guignon (2014) uncovered gaps at the relational-relational level, with reported dual membership in their adoptive and birth families leading to feelings of uncertainty and unease in regards to their place within either family unit. Similarly, gender may be a realm of one's self that generate dissonance between different personal relationships and within oneself.

\section{CTI in Studies of Gender and Sexuality}

While communication theories are generally applicable for interdisciplinary uses, CTI is 
a particularly practical framework for scholars of gender and sexuality. Previous studies have explored the ways in which individuals can experience identity gaps and implement discursive strategies to manage societal pressures and expectations. Men can feel societal pressure to pursue fitness in order to achieve a socially acceptable body standard. This drive for a particular, societally endorsed type of masculine identity and muscularity can cause men to experience misalignment between the personal, relational, and enacted frames. The discursive strategies used to manage the uncertainty produced by these identity gaps include excessive body discipline, forceful negotiation, and constant comparison (Wagner, 2017). In a similar study employing the identity gap tenets of CTI, female athletes and the pressures placed upon them by their coaches and the demands of their sport were analyzed. The women reported issues of identity management, as they experienced pressure both to maintain the "thin-ideal" female body promoted in media while simultaneously growing physical fitness. These dialectical tensions led to the development of identity gaps at all four levels of identity as conceptualized in CTI (Beckner \& Record, 2016).

CTI has been shown to yield fruitful data in studies exploring participants' varying sexualities. Non-heterosexual individuals in the workplace have reported experiencing identity gaps at the personal-relational and personal-communal level. Respondents noted that while policies existed on company record to protect the interests of non-heterosexual employees, those policies were rarely put into practice, or either implicitly or tacitly ignored (Compton, 2016). The perceived lack of support or protection for non-heterosexual individuals leads to specific gaps between personally-held identities and the identities enacted in the communal and relational spaces at the work place; this marginalization and subsequent uncertainty and identity gap development would not occur in heterosexual individuals. Scholarly understanding of the 
development of these constructs is well-based within a further overview of measures through which it is assessed.

\section{Personal-Personal Identity Gaps}

Using the framework of CTI, the differences between an individual's personally held beliefs about his or her identity and the ways in which these identities are enacted have been studied extensively. However, it is also possible that appreciable and impactful differences can develop between an individual's current personally held identity and their goal, desired, or ultimate identity. This achievement of a more preferred or truthful identity has been studied anecdotally for time immemorial, namely through fiction and non-fiction writing.

A novel that seeks to capture this difficult — and often messy—process of an individual's personal growth and self-realization of identity is referred to as a bildungsroman. According to Mirriam-Webster, a bildungsroman is "a novel about the moral and psychological growth of the main character" and often focuses on the progression of a youth's development of personal identity from childhood through young adulthood. Novels such as Jane Eyre and The Catcher in the Rye focus on the development of self that occurs throughout a young adult's lifetime, wherein the main character experiences dissatisfaction with their identity and seek to develop a different, more satisfying, or truthful personally-held identity. These characters typically achieve this self-actualization and maturity through life experience, as seen in Jane Eyre's traumatic time spent at Lowood School, or Holden Caulfield's adventures through New York City in Catcher.

These characters also refine their identities via advice or inspiration from other characters within the novel: Holden is reminded of the innocence he once held by his sister, Phoebe, and Jane is reminded to live life without resentment or anger by her fellow schoolgirl, Helen Burns.

While these coming-of-age narratives are common in literature, no extant research in 
communication studies examines the stress or strain which occurs when individuals' assessments of their current identity state do not align with their preferred, or ideal identity state. This potential dissonance would exist_-using Hecht's CTI language — within rather than between layers, at the personal level. Thus, the newly conceived identity gap is referred to as personalpersonal.

\section{Bem Sex Role Inventory}

The Bem Sex Role Inventory (BSRI) was first published by Sandra Bem in 1974. The measure has been used extensively in a number of disciplines to discern how - using traditional conceptualizations - masculine and feminine individuals differ based on their reported personality traits. In the study of communication, researchers have used the BSRI to determine whether or not individuals with a more traditionally masculine gender identity differ in their use of touch avoidance when compared to traditionally feminine individuals; results indicate that Bem's conceptualizations of masculinity and femininity do impact touch preferences, as compared to traditionally feminine women, traditionally masculine men were more avoidant of same-sex touch (Martin \& Anderson, 1993).

After substantial use by both outside researchers and Bem herself throughout the 1970s, the Short-Form version of the BSRI was developed as a more concise, accurate measure of traditionally masculine and feminine traits (Bem, 1981). Bem's ultimate goal in creating the measure was to qualitatively record the ways in which psychological androgyny - the possession of both traditionally masculine traits, such as forcefulness and aggressiveness, and traditionally feminine traits, such as warmth and tenderness — can impact an individual's well-being.

Sandra Bem extensively studied the implications of individuals who align with different points on the sex role index, in particular those individuals identified as "androgynous," who 
scored high in both traditionally masculine and feminine sex traits on the scale. Bem's subsequent studies of these individuals found that androgynous individuals could switch into more masculine or feminine behaviors depending on the communicative or relational situation; meanwhile, non-androgynous individuals had a harder time adjusting in scenarios that called for either more nurturing or more aggressive behaviors (Bem, 1975).

Bem and her colleagues also discovered and noted a difference between androgynous individuals and those who did not score highly on either masculine or feminine scales, later known as "undifferentiated" individuals. While Bem is known for her focus on androgynous individuals, she frequently studied undifferentiated individuals to contrast the benefits of androgynous behaviors and lifestyles. In a 1976 piece, Bem asserted that while androgynous and undifferentiated individuals are similar in their lack of alignment with either masculinity or femininity, there was a clear difference in the reported levels of self-esteem and behavior inhibition between the two groups, with undifferentiated individuals reporting lower levels of self-esteem and higher behavioral inhibitions. The difference between androgynous and undifferentiated individuals continued to manifest in behaviors covered in further studies. In the Bem (1997) study, androgynous and undifferentiated individuals did not differ in their attitudes toward women, locus of control, Machiavellianism, or attitudes toward problem-solving, but they did differ on self esteem, with androgynous individuals (high-high) consistently reporting higher self esteem than undifferentiated individuals (low-low); this was consistent with a similar study that analyzed the ability of androgynous individuals to switch from masculine independence to feminine nurturance, dependent on experimental scenario (Bem, Martenya, \& Watson, 1996). These results suggest that androgynous and undifferentiated individuals are distinct in their perceptions of personal identity and self-satisfaction, but not in their enacted 
behaviors or expressed opinions. In this case, the lack of significant differences between androgynous and undifferentiated individuals may be as meaningful (given colloquial assumptions), as the significant differences.

Communication scholars Jim McCroskey and Virginia Richmond also studied the effects masculine and feminine traits have on perceptions by others. McCroskey and Richmond used early research and the specific traits of masculine assertiveness and feminine responsiveness as conceptualized by Bem and to create a measure of sociocommunicative style. Richmond and Martin (1998) note that both Bem's scale and the sociocommunicative scale measure communication styles, though Bem's work predates the latter communication work by McCroskey and Richmond. The sociocommunicative scale was originally titled by the binary it examined: assertiveness and responsiveness (Richmond \& McCroskey, 1990). Components of assertiveness include an individual's ability to begin and end conversations, their increased orientation toward holding more task-related conversations, and the greater likelihood of them successfully standing up for or defending themselves; components of responsiveness include being sensitive to the needs and feelings of others, placing an emphasis on the dyadic nature of relationships, and exhibiting compassionate behaviors (Richmond \& Martin, 1998). Assertiveness and responsiveness, as defined by the sociocommunicative scale, correlate directly to Bem's ideas of traditional masculinity and femininity, respectively (Richmond \& Martin, 1998).

While Bem's notions of assertiveness being a traditionally masculine trait and responsiveness as a feminine trait predates the development of the sociocommunicative scale, Richmond and McCroskey's work brought Bem's concepts of gender norms and masculine and feminine behaviors solidly into the realm of communication and communication studies. A 1996 
study by Wooten and McCroskey utilized the sociocommunicative scale, and found that both responsive (feminine) teachers and assertive (masculine) teachers were trusted by their students; however, only highly-assertive students experienced increased trust with highly-assertive teachers. Based on the data gathered by Wooten and McCroskey, teachers high in both assertiveness and responsiveness would be the most appealing and trustworthy to the greatest variety of students. Given that McCroskey and Richmond's conceptualizations (and instrument) so closely mirror Bem's, Wotten, and McCroskey’s study supports Bem’s notion that androgynous individuals are more capable of adjusting their communication styles in accordance with their surroundings, making them more effective communicators (Bem, 1975).

Recent studies have shown correlations between androgyny and life satisfaction in a variety of cultures. In a 2001 piece on coping strategies and gender norms, androgynous individuals were the most likely to use problem-oriented coping, due to their ability to successfully use both assertiveness and responsiveness in navigating difficult and stressful situations (Lipińska-Grobelny). In the same study, it was also found that androgynous individuals had the highest reported levels of life satisfaction. Another study that used a sex-role ideology scale in a South African population found that the presence of non-traditional gender role attitudes predicted higher satisfaction with life (Mokgatlhe \& Schoeman, 1998).

Conceptualizations of gender and gender identity have evolved substantially since Bem first developed her scale in 1974; both societally and in scholarship, ideas of gender fluidity and the understanding that gender is not a biologically-bound identity have developed over the last 40 years. Sandra Bem initially developed the BSRI and conducted her studies under the assumption that an androgynous individual would have equally masculine and feminine traits, and a sex-typed individual (i.e., masculine or feminine) would have more traits in one category 
than another (Bem, 1974; Bem \& Lewis, 1975). However, with the publication of her professional manual of the BSRI in 1981, Bem altered the scoring technique: not wishing to restrict the respondents to a binary, Bem believed the scoring should be done in a split-median format, wherein individuals who scored about the median (50\%) of both masculine and feminine trait categories would be considered to be androgynous, and sex-typed individual would be identified if a participant scored about the median in one category, but not in the other. This reconceptualization of the BSRI shaped future research with the scale, allowing more flexibility of individual responses and a wider conceptualization of gender fluidity and identity.

Researchers in a 2006 piece (Johnson et al.) found support for the improvement of the BSRI's scoring technique from a categorical or continuous sex-role orientation measurement. The authors suggest that categorical sex-role associations support Bem's original hypothesis about the importance of androgynous categorization on well-being scores. However, when masculinity and femininity and well-being were all scored as continuous measures, a negative association between femininity and well-being as well as a positive association between masculinity and well-being were uncovered (Johnson et al., 2006). More recent studies, therefore, show a changing dynamic of gender roles and their societal interactions and implications that have evolved since Bem's initial research, which bears a closer examination. Popular press pieces have also covered the changing landscape for gender identities; in recent months, magazine and television news pieces have made a concerted effort to disseminate information on gender norms and the differences between gendered expression and identity and biological sex (e.g., Adams, 2017; "Gender and Sexuality"). Concepts and terminology covered and defined in these articles include cisgender, bigender, and two-spirit; while the exposure of the general population to these identities and titles is important, these and other specific labels 
capturing the diversity of gender identities will neither be directly assessed nor employed in this study. By providing interviews with queer and gender-non-conforming individuals, as well as glossaries and definitions of terminologies such as "gender non-binary" or "gender conconforming," these popular press pieces likely help to shape public understanding of nontraditional identifications and increase awareness and empathy. By simply presenting this information, these publications create discourse that normalizes the existence of diverse sexual and gender identities. These developments in individual consciousness, scholarly understanding, and public discourses alter the perspectives that should be taken when conducting studies on gender, and necessitates updated studies using the BSRI to ensure its heurism and applicability in a modern and more progressive context.

Bem's initial conceptualization of the sex role index did not take into consideration the importance an individual may place on gender norms or expectations. The salience of a subject is considered to be "the extent to which" the topic "is present in everyday thoughts, feelings, and behaviors" of an individual (Palgi, Amit Shrira \& Menachem Ben-Ezra, 2015, p. 9). While Bem did not consider the importance an individual placed on his or her sex role and the personallyheld opinions toward the societal expectations placed on gender norms and behaviors, modern scholars implementing the BSRI or analyzing gender differences should consider measuring gender salience as potential moderating factor in their research. Bittner and Goodyear-Grant (2017) took such an approach when analyzing gender differences in political attitudes of men and women across Canada. However, instead of assuming mere gender differences - such that political attitudes and interests would be homogenous within the binary gender groups, and political gaps would exist between men and women - the researchers proposed that a participant's gender salience would moderate his or her political partisanship. Results indicated 
support for the importance of gender salience in the assessment of the population's political beliefs. Specifically, women whose gender identity was particularly salient were more likely to have liberal political beliefs when compared to women with low levels of gender salience. This study therefore suggests the importance of considering more than just the gender binary when crafting research projects and hypotheses; rather, participants' gender salience can be a substantial moderating force, accounting for within-gender differences in data collected.

\section{Rationale}

Building on the research already developed by previous gender communication scholars, the purpose of this study is to examine the ways in which CTI's conceptualization of identity gaps may appear in the lives of individuals who do or do not not enact traditional sex roles.

Based upon this previous research, the following hypotheses are forwarded:

H1: Gaps at the personal-personal, personal-relational, and personal-enacted levels are negatively correlated with life satisfaction.

$\mathrm{H} 2$ : The relationships between gaps at the personal-personal, personal-relational, and personal-enacted levels and life satisfaction are moderated by efficacy.

H3: Gaps at the personal-relational level are negatively related to relational satisfaction.

H4: The negative relationship between personal-relational gaps and relational satisfaction is moderated by efficacy.

H5: Relational satisfaction is positively correlated with life satisfaction.

Previous research on CTI generally (and identity gaps, discursive strategies, and gender specifically) led to the following hypothesis about the life satisfaction of androgynous individuals

H6: The negative relationship between femininity and life satisfaction will be moderated 
by masculinity scores. When masculinity is high, the negative relationship between femininity and satisfaction becomes positive. When masculinity is low, there is no change to the negative relationship between femininity and satisfaction.

Finally, the role of gender salience was examined in the data:

RQ1: When controlling for gender salience, do the hypothesized relationships between identity gaps (personal-personal, personal-relational, and personal-enacted) and satisfaction outcomes (life satisfaction and relationship satisfaction) change? 


\section{CHAPTER TWO}

\section{Method}

\section{Participants and Procedures}

Two hundred forty-nine participants were recruited through convenience sampling in undergraduate, introductory communication classes at a large mid-Atlantic university. After obtaining human subjects approval from the Institutional Review Board, department procedures for obtaining participants were followed, and the study was posted on the department's website and on the department's bulletin board for research opportunities. Participants received a research receipt after completing the study, which took approximately 20 minutes to complete, and had the opportunity to receive minimal extra credit in a communication course for their participation. After eliminating incomplete data and participants who failed the attention-check questions, the final participant count was 229.

The questionnaire opened with the Short-Form Bem Sex Role Inventory (Bem, 1981) and gender salience items, followed by the first conceptualization of the personal-personal measure and both the Personal-Enacted and Personal-Relational Identity Gap Scales (Jung \& Hecht, 2004). Following the conclusion of the Personal-Relational measure, Huston, McHale, and Crouter's (1986) Relationship Satisfaction Scale was included in the survey materials. The Satisfaction with Life Scale (Diener, Emmons, Larsen, \& Griffin, 1985) and the Sherer, et al. (1982) general and social self-efficacy scale followed. The survey concluded with basic demographic items. All of the aforementioned measurements and procedures are described in the next section precisely as they appeared to the participants.

\section{Instrumentation}

Life satisfaction. The Satisfaction with Life Scale (Diener, Emmons, Larsen, \& Griffin, 
1985 ) is a five-item scale intended to assess a participants' overall well-being on a 7-point Likert scale ranging from strongly disagree (1) to strongly agree (7). Example items include "In most ways, my life is close to my ideal," and "The conditions of my life are excellent." Cronbach's alpha from this study was $.86(M=5.24, S D=1.15)$.

Identity gaps. The Personal-Enacted Identity Gap Scale (Jung \& Hecht, 2004) includes eleven items designed to measure discrepancies between an individual's personal and enacted identities on a 7-point Likert scale ranging from strongly disagree (1) to strongly agree (7). Examples of the Personal-Enacted Identity Gap Scale items include "I do not express the real me when I think it is different from my communication partners' expectations" and "I sometimes mislead my communication partners about who I really am." Two items from the original scale were edited to include references to gender identity: "I express my gender identity in a certain way that is not the real me when communicating with my communication partners," and "I speak truthfully to my communication partners about my gender identity." Jung and Hecht (2004) reported a Cronbach's alpha of .89 for the scale. Cronbach's alpha for this study was .88 $(M=2.50, S D=1.10)$.

The Personal-Relational Identity Gap Scale (Jung \& Hecht, 2004) includes eleven items designed to measure discrepancies between an individual's personal and relational identities on a 7-point Likert scale ranging from strongly disagree (1) to strongly agree (7). This scale was edited for the purposes of this study to focus participants' answers on a single, close other and the interactions within that particular relationship. Participants were encouraged to think of a single, close other and to write both their relationship to the close other (i.e., "mother," "sister," "boyfriend," "best friend") and to type the initials of the close other in a short-answer box in the survey. The scale items were also edited to include the phrase "this person," instead of "my 
communication partners.” Examples of the Personal-Relational Identity Gap Scale items implemented in this study include "I feel that this person does not realize that I have been changing and still portrays me based on my past images," and "I feel that the person I'm thinking about has correct information about me." Two items from the original scale were further edited to include references to gender identity: "I feel that this person has wrong images of my gender identity," and "I feel that this person portrays my gender identity not based on information provided by myself but information from other sources." Jung and Hecht (2004) reported a Cronbach's alpha of .86 for the scale. Initial Cronbach's alpha for this study was .77 ( $M=2.32$, $S D=.95)$. To improve reliability from .77 to .86 , one item, "I feel that this person knows who I used to be when they portray me," was removed. It is likely due to the relatively unclear wording of the prompt—which could refer either to a positive association with the long-standing and affirmative relationship relational partner, or a negative association of the relational partner's inability to accept the participant's changing identity development—-that the reliability of the prompt was impacted. The now 10-item personal-relational scale had a mean of $2.11(\mathrm{SD}=.87)$ and was used in all hypothesis testing.

The Personal-Personal Identity Gap Scale was developed by the author specifically for this study. These questions were modelled on the wording of the personal-enacted and personalrelational scales as developed by Jung and Hecht (2004), with nuances geared toward assessing the presence of differences between an individual's personal conceptualization of self, and the desired or goal identity. An initial list of 13 statements were developed by the author, paralleling language of the other gap scales whenever possible, which were further workshopped with her advisor to maximize clarity of wording, as well accuracy in relation to the variable being assessed. A total of 15 statements were ultimately developed and implemented as the personal- 
personal measure in this study. Example items include "I feel that I am the best version of myself I can be," "I am living my most authentic life," and "I have yet to become the 'true' version of myself." Cronbach's alpha for these items in this study was $.82(M=2.82, S D=1.09)$.

All of the gap scales were entered into an exploratory factor analysis, and Cronbach's alphas assessed. These served as a preliminary assessment of the scales' utility. Correlations between the personal-personal and the personal-enacted scale tested the convergent validity of the proposed personal-personal measure.

Relationship satisfaction. Huston, McHale, and Crouter's (1986) established scale was employed to measure the satisfaction the personal relationship the participant considered while answering the personal-relational gap questions. Cronbach's alpha from this study was .95 ( $M=$ $6.21, S D=.99)$. As prescribed, the summed 8-items were correlated with with the global item to further demonstrate the ability of the 8-item measure to assess satisfaction in a particular relationship, $r=.73, p<.001$. This scale included items ranging from "miserable" to "enjoyable," "free" to "tied down," and "worthwhile" to "useless."

Sex role (masculinity and femininity). The Short Form Bem Sex Role Inventory (Bem, 1981) is a thirty-item scale that measures the presence or enactment of feminine and masculine traits and behaviors on a 7-point Likert scale ranging from Almost Never True (1) to Almost Always True (7). The Short Form BSRI is separated into three subscales: Masculine, Feminine, and filler or control variables, which were not scored. The three types of items alternated, and were staggered throughout the measure, such that the Masculine items were numbers 1, 4, 7, 10, 13, 16, 19, 22, 25, and 28; Feminine items were numbers 2, 5, 8, 11, 14, 17, 20, 23, 26, and 29; and the filler items were numbers 3, 6, 9, 12, 15, 18, 21, 24, 27, and 30 on the scale. Examples of the Masculine items include "assertive" and "dominant." Examples of the Feminine items 
include "loves children," and "understanding." Examples of the filler items include "adaptable" and "moody." A 1978 Stanford study (as reported in Bem, 1981) reported Cronbach's alpha scores ranging from $.85-.86$ for the masculine scale, and Cronbach's alpha scores ranging from .84-.87 for the feminine scale. Campbell, Gillaspy, and Thompson (1997) reported a Cronbach's alpha of .82 for the masculine scale, and a Cronbach's alpha of .89 for the feminine scale. This study found a Cronbach's alpha of $.78(M=4.83, S D=.79)$ for the masculine subscale and .88 $(M=5.37, S D=.96)$ for the feminine subscale.

Gender salience. One question from Yang (2016) was adapted to ask "How important do you think issues of gender identity or gender expression are in comparison to other societal issues?” Two questions were adapted from Letzter-Pouw, Shrira, Ben-Ezra, and Palgi's 2014 Holocaust Salience Scale, as operationalized in Palgi, Shrira, and Ben-Ezra (2015). These questions were altered to ask about gender salience instead of Holocaust salience: "I frequently think about gender," and "I am interested in gender more than most of the people I know." These two questions were measured on five-point Likert scales ranging from "strongly disagree" to “strongly agree." The Cronbach's alpha for this adapted 3-item scale in this study was .89 $(M=$ $3.36, S D=1.57)$

Four questions intended to gauge participants' gender salience were developed specifically for this study: A binary question asked, "Do you care about gender or gender-related issues?" There were 138 (58.5\%) people who indicated yes, and 98 (41.5\%) people who indicated no. Three additional questions were posed on sliding scales ranging from 0 to 100 , as operationalized by Yang (2016): "How much do you care about gender or gender-related issues," "How often do you discuss gender or gender-related issues with other people," and "How important do you find issues of gender identity and gender expression to be in relation to other 
local or national issues and world events?" Cronbach's alpha for the three sliding scales in this study was $.87(\mathrm{M}=41.64, \mathrm{SD}=25.49)$.

Self-efficacy. Sherer, et al. (1982) created a 23-item and 14-point scale which measures both general and social self-efficacy. The 14 points range from "strongly disagree" to "strongly agree," with 12 unlabeled points between the two labelled anchor points. Due to the potentially wide range of potential responses without accompanying verbal definitions to define the 12 points between the labelled poles on the scale, the scale was condensed and converted to a 7point Likert-type scale ranging from "strongly disagree" to "strongly agree," with the previouslyunlabeled points being labelled "disagree," "slightly disagree," "neither agree or disagree," "slightly agree," and "agree," in that order. The questions from the original Sherer, et al. (1982) publication were retained. Example items include "I give up on things before completing them," "I am a self-reliant person," and "When I make plans, I am certain I can make them work." Cronbach's alpha for this study was $.90(M=4.84, S D=.87)$.

Attention check questions. In order to ensure that data collected from surveys were from attentive participants, a series of check questions were placed at the end of the survey. Using examples from Peer, Vosgaru, and Acquisti (2014), participants were asked if they had ever experienced a fatal heart attack and how many moons the planet Earth has. After data collection, one participant failed an attention check question, by reporting that Earth had two moons. As a result, this participant's responses were not included in the data analysis.

\section{Analysis}

First, all data was prepared for analysis (i.e., responses removed when greater than $5 \%$ data missing; reverse items recoded; mean, standard deviations, and range calculated; normal distribution assessed yielding all acceptable values for skew and kurtosis). Second, the newly- 
created Personal-Personal (P-P) Identity Gap Scale was assessed using the following procedures: after the participants took the original, 15-item scale, a Cronbach's alpha for both the scale and for each of the items was calculated in order to assess and determine the best and fewest items to include in future uses of the scale.

Given the conceptual similarities between the three CTI subscales (personal-personal, personal-relational, and personal-enacted), an exploratory factor analysis (EFA) was conducted, using maximum likelihood model as the extraction method and an oblimin rotation for the correlated factors of the subscales. The EFA yielded 8 factors. Tables 2, 3, and 4 show these factors for the three subscales, only including eigen values at or above the cutoff of .32, as recommended by Costello and Osborne (2005).

The eight factors generated by the EFA were analyzed more closely to identify the shared themes within the items. Factor 1 includes almost every item across the three subscales (except for item two of the personal-personal scale). The majority of the other obtainable loadings (over the .32 cutoff) emerge in Factors 2, 3, and 4. Factor 2 contains items that address the individual's sense of identity fulfillment, which were most of the reverse coded and positively-valenced items (i.e., "I freely express the real me," "I feel this person sees me as I see myself"). Factor 3 contains items across all three subscales that deal with temporal issues and changing identities over time (i.e., "I feel that this person does not realize that I have been changing and still portrays me based on my past images," "I am far from the person I one day hope to become"). Among the three items with loadings above .32 for Factor 4, there is a theme of expression and impression-making, but other items of expression (i.e., "I freely express the real me," "When I communicate with others, they get to know the 'real me"') did not fall under Factor 4. Factors 5 through 8 yielded item-loadings below the .32 cutoff, with the exception of two items. 
In further exploration, the three identity gap subscales were run as separate and individual analyses, with the factors unrotated. Doing so resulted in three factors for the personal-personal subscale, three factors for the personal-enacted subscale, and two factors for the personalrelational subscale. The majority of items on each of the subscales loaded on multiple factors. While making substantial efforts to refine these measures is a viable pursuit for future scholarly endeavors, this population's data will be interpreted using the measures as they have been developed and consistently utilized in previous research.

As the complexities of gender identification and societally-enforced sex roles are expected to impact the identity development and subsequent satisfaction of young adult Americans, the following hypotheses were tested:

H1: Gaps at the personal-personal, personal-relational, and personal-enacted levels are negatively correlated with life satisfaction.

H2: The relationships between life satisfaction and gaps at the personal-personal, personal-relational, and personal-enacted levels are moderated by efficacy. H3: Gaps at the personal-relational level are negatively related to relational satisfaction. H4: The negative relationship between personal-relational gaps and relational satisfaction is moderated by efficacy.

H5: Relational satisfaction is positively correlated with life satisfaction.

In an attempt to replicate Bem's original findings on the dissatisfaction caused by high levels of femininity, and the satisfaction caused by androgyny, the following hypothesis was tested:

H6: The negative relationship between femininity and life satisfaction will be moderated by masculinity scores. When masculinity is high, the negative relationship between femininity and satisfaction becomes positive. When masculinity is low, there is no 
change to the negative relationship between femininity and satisfaction.

Because the salience or importance of gender in an individual's life was expected to be important in said individual's gender identity development and the impacts of societal sex roles, the data was analyzed in order to answer the following research question:

RQ1: When controlling for gender salience, do the hypothesized relationships between identity gaps (personal-personal, personal-relational, and personal-enacted) and satisfaction outcomes (life satisfaction and relationship satisfaction) change? 


\section{CHAPTER THREE}

\section{Results}

A correlation matrix of all tested variables is in Table 1. A series of Pearson-product moment correlations fully support H1. The presence of personal-personal (P-P), personal-enacted (P-E), and personal-relational (P-R) gaps were each negatively correlated with life satisfaction. These are shown in Table 1.

$\mathrm{H} 2$ predicted that the relationship between participant life satisfaction and their identity gaps at the personal-personal, personal-relational, and personal-enacted levels would be moderated by efficacy. This hypothesis was tested through regressions and Hayes (2013) PROCESS macro for SPSS (Model 1) for assessing moderation. Due to the fact that the three identity gaps were strongly correlated with each other (See Table 1), the focal predictors were run independently (i.e., as three separate tests), as opposed to one regression of all three focal predictors.

First, the relationship between P-R gap on reported levels of life satisfaction was assessed $\left(\Delta R^{2}=.02, F(1,224)=6.16, p=.01\right)$. Efficacy was a significant moderator $(\beta=-.18, \mathrm{SE}=.07$, $95 \% \mathrm{CI}=-.33,-.04)$. The conditional effect of the P-R gap on life satisfaction was proved using the pick-a-point method (Hayes 2013), in which the moderating effects were examined at one standard deviation away from the mean score (i.e., -1 SD, 0 SD, 1 SD). As shown in Figure 2, the positive relationship between personal-relational identity gaps and life satisfaction was affected by efficacy such that at lower levels of efficacy, the relationship between the gap and satisfaction was nonsignificant ( $b=-.06, p=.42$ ). At moderate levels of efficacy, efficacy's moderating effect on the relationship between the existence of the personal-relational gap and the participant's satisfaction was significant $(b=-.22, p=.002)$. At high levels of efficacy, the 
relationship between the personal-relational gap and satisfaction was significant, and the most pronounced of the three conditions $(b=-.38, p<.001)$ - in other words, the higher an individual's efficacy, the greater the moderating effect on the gap and satisfaction.

Second, the association between the P-P gap and life satisfaction was assessed. The moderating effect of efficacy was non-significant $(\beta=-.11, \mathrm{SE}=.07, p=.12,95 \% \mathrm{CI}=-.24$, $.03)$.

Third, the association between P-E and life satisfaction was assessed. The moderating effect of efficacy on the relationship between the P-E and life satisfaction was non-significant ( $\beta$ $=-.05, \mathrm{SE}=.07, p=.48,95 \% \mathrm{CI}=-.18, .09)$.

$\mathrm{H} 2$ was partially supported, as there was a moderation of the personal-relational gap's relationship on life satisfaction such that as efficacy levels increased, its moderating effect on the became significant; however, there were no conditional effects by efficacy for either of the other focal predictors (P-E or P-P).

$\mathrm{H} 3$ predicted that personal-relational gaps would be negatively related to relational satisfaction. Results of the correlation matrix (Table 1) offer support for $\mathrm{H} 3$, such that the presence of the P-R gap was negatively correlated to relational satisfaction.

Using the same procedures described for testing H2's moderations, the author ran a moderation to test the $\mathrm{H} 4$ prediction of a moderating effect from efficacy on the negative relationship between the P-R gap and relational satisfaction. The results were non-significant $(\beta$ $=.10, \mathrm{SE}=.06, p=.10,95 \% \mathrm{CI}=-.02, .23)$.

$\mathrm{H} 5$ predicted that participants' relational satisfaction would be positively correlated to their life satisfaction. Results of the correlation matrix in Table 1 indicate support for H5, such that relational satisfaction was positively correlated with life satisfaction. 
H6 predicted that there would be a negative correlation between femininity scores and life satisfaction, and that this correlation would be moderated by masculinity. Again employing Hayes' moderation procedures and program, this significant model, $R^{2}=.15, F(3,225)=13.19$, $p<.01$, revealed a positive relationship between femininity and life satisfaction. The moderating effect of masculinity on the relationship between femininity and life satisfaction only approached significance $(\beta=-.16, S E=.08, p=.06,95 \% \mathrm{CI}$ : -.33 to .01$)$. As shown in Figure 2, the slope of femininity's positive relationship with life satisfaction is steepest for the lowest masculinity group (4.03 on 7-point scale), and less steep for the mean (4.82) and high-ranking (5.6) masculinity groups. Therefore, H6 was not supported.

To address the research question as to the role of gender salience in the gap and satisfaction relationships, gender salience was employed as as a control variable. As a preliminary analysis, the differences between those in the "care about gender salience" and those in the "do not care about gender salience" groups (data from the dichotomous, closed-ended survey question) were analyzed using using independent samples t-tests. An independent samples t-test showed few differences between salient and non-salient groups, with the exception of femininity, the gender salience slider, and the continuous three-item gender salience measure (See Table 5). This suggested that there would be minimal or no differences based on gender salience. However, gender salience's potential moderating effect was still tested.

To directly assess this RQ, the identity gaps and satisfaction outcomes were assessed using a series of partial correlations while controlling for gender salience using the three-item measure developed in this study. Results of the partial correlations (Table 6) indicate that the relationships between the three gap measures (P-P, P-E, and P-R) and and the two satisfaction measures (life and relationship) all remained significant when controlling for gender salience. 


\section{CHAPTER FOUR}

\section{Discussion}

Through this study, I sought to analyze the complexities of gender identity development and the adherence to —or departure from—gender norms in an emerging adult population. Specifically, this study hoped to replicate the findings of previous studies which used Hecht's Communication Theory of Identity, as I argued that issues of gender identity development and pressures of societally-reinforced sex roles would lead to the development of identity gaps, which would further lead to dissatisfaction in one's life and relationships. This study joins recent research examining the pressures of sex roles and the dissatisfaction inherent in gendered identity gaps (Beckner \& Record, 2016; Wagner, 2017) and the exploration of within-layer identity gaps (Colaner, Halliwell, \& Guignon, 2014). However, this thesis also contributed uniquely to communication literature, by conceptualizing and implementing an entirely new within-gaps measure and challenging the established Bem hypotheses for gendered expectations. Results of this study also suggest that additional identity gap measures can (and should) be developed and employed by future researchers, and that the big picture social understanding of gender - and the valuation of traditionally feminine attributes — has changed since Bem began her work on sex roles in the 1970s.

Implemented in this study was a new within-gaps measure: the Personal-Personal (P-P) Gap Scale. The P-P gap scale was hypothesized to function in a way similar to the established Hecht scales, but focus more specifically on respondents' internally- and personally-held beliefs in regard to identity development. The P-P measure was implemented in the hopes of measuring a gap between an actual (current) and ought (ideal) self in relation to emerging adults' gender identity specifically; however, the scale was also developed in order to be used in further CTI 
research seeking to measure internal identity gaps generally, not just for those studies and researchers interested in gender. Two characteristics—-participant self-efficacy and participants' reported gender salience — were hypothesized to be the most impactful potential moderators, and were tested in the data collected. This study also implemented Bem's Sex Role Index in a modern population and re-tested Bem's hypotheses on the satisfying nature of androgynous gender identities, and the dissatisfying nature of highly feminine identities. These topics were explored in the data analysis, and will be discussed more thoroughly below.

\section{Personal-Personal Gaps and Identity Gap Measurement Considerations}

Previous studies implementing CTI indicated that the presence of identity gaps is a painful and dissatisfying experience (Hecht et al., 2002; Jung \& Hecht, 2004; Maeda \& Hecht, 2012; Wadsworth, Hecht, \& Jung, 2008). Based on the results of H1, this study serves as replication for these findings, as the presence of identity gaps inflicted harm and discomfort in the surveyed individuals. Participants in this study indicated that possessing identity gaps was a globally unsatisfying experience; further, the presence of the personal-relational gap was negatively related to relational satisfaction in this sample (H3). The results of this study suggest that the CTI and identity gap measures are accurately measuring the experiences conceptualized by Hecht.

This study also suggests that additional gap measures, which move beyond those initially forwarded by Jung and Hecht (2004) can and should be developed, and then effectively implemented. This study sought to explore a within-layer gap, such as the relational-relational gap proposed by Colaner, Halliwell, and Guignon (2014), which is conceptualized as existing at only one of the four identity layers. This study proposed an identity measure conceptualized as the personal-personal gap, theorized to exist between an ideal self and the self as seeming to 
currently exist. As tested by the new P-P measure, this gap manifested in this study, and functioned similarly to the established personal-enacted and personal-relational gap scales (H1). Specifically, the presence of the personal-personal gap was negatively correlated with life satisfaction, such that those participants who experienced a perceived distance between their current and ideal selves were less satisfied with their lives, whereas those who felt their personal identities were ideal were more satisfied.

However, given the descriptive statistics for the created P-P scale $(M=2.82, S D=1.09)$, it is evident that most of the participants in the study were scoring below the median on the 7point measure; therefore, emerging adults were not universally experiencing the P-P identity gap as it was conceptualized in this study. However, as the range for these particular data was from 1.00 to 5.40, it is also evident that a portion of the respondents were scoring higher on the P-P scale, indicating that a number of young adult respondents were experiencing a disconnect between the gendered identity possessed and their idealized gender identity. Therefore, extrapolating from the sample population surveyed, we derive that a minority population of today's emerging adults do not all consider themselves to be living the as the "self" they wish to be, or to have developed a satisfactory gender identity. The personal-personal gap measure was implemented to include several items directly measuring breaks in gender identity, so these results indicate that gender and gender expression is an ongoing and continually-developing facet of some individuals' identities, and that the gender norms and societally-developed and reified sex roles continue to impact this development in particular populations of emerging adults.

This study sought to broadly examine the potential impacts gender salience has on gender identity development and satisfaction. The results of RQ1 indicated that an individual's gender salience bares little impact on the development of the personal-enacted and personal-relational 
gaps that involve gender. Though there is merit to the idea of gender performativity proposed by Butler (1990), wherein the more aware of gender expectations a person becomes, the more likely that individual is to "perform" according to those expectations, there may be cohort trends toward understanding gender's complexity. The trend of gendered identity gaps impacting the satisfaction levels of today's emergent adults—regardless of gender salience—may be attributable to a more broadened conceptualization of gender as compared to previous cohorts.

In the initial CTI publications, Hecht and his colleagues developed only a small number of scales intended to measure gaps solely between separate layers of identity. However, later publications using CTI have noted the possibility and importance of measuring gaps that exist within a single identity layer (Colaner, Halliwell, \& Guignon, 2014). It is based on the initial work of communication researchers seeking updated within-gap measures, as well as the dissonant identity experiences explored in feminist research and Young Adult fiction and nonfiction, that the concept of the personal-personal gap measure was formed. While the personalpersonal gap scale was initially conceptualized to measure identity gaps resulting from gender expectations, results from this study show that the relationship between the presence of the personal-personal gap and decreased life and relational satisfaction persisted even after controlling for the effects of gender salience (RQ1). These results suggest that the personalpersonal gap scale could be used effectively in studies which do not involve issues related to gender identity or gender salience specifically. Thus, future studies using CTI measures, and those researchers particularly interested in within-level gaps, should consider the personalpersonal scale proposed in this study. The personal-personal measure affords a unique opportunity to target internalized or closely-held identities which may not manifest openly, or be otherwise easily assessed. If the personal-personal measure is not germane to another study or 
researcher's interests, this study's successful implementation of an entirely new CTI scale still can serve as inspiration for other researchers who which to examine a previously-understudied identity phenomenon. Other communication researchers should feel emboldened to create specific measures, modelled on the initial CTI gap measures, which could more accurately pinpoint the particular identity-related issues important to a given study.

Efficacy was proposed as a moderator between gap presence and outcomes in this study. When examining the impact of efficacy as a moderator in the relationships between the presence of identity gaps and reported levels of efficacy, it was discovered that efficacy moderated the relationship between the personal-relational (P-R) gap and reported levels of life satisfaction $(\mathrm{H} 2)$; interestingly, efficacy only moderated the impacts of P-R on life satisfaction, not for relational satisfaction (H4), though life satisfaction and relational satisfaction are correlated (H5), and the personal-relational gap was negatively related to relational satisfaction in this sample (H3). These results suggest that additional factors, outside of an individual's efficacy, impact his or her relational satisfaction.

While the initial hypothesis was developed under the belief that efficacy would be a benefit to the negative influence of gaps on wellbeing, the data from this study indicates that the being highly efficacious could actually contribute to feelings of dissatisfaction. Highly efficacious individuals may feel worse, more troubled, or powerless if they are unable or incapable of closing these identity gaps due to societal, cultural, or relational pressures outside their locus of control. So while efficacy may be beneficial in spaces where agentic problemsolving, planning, or strategizing can be efficiently enacted to benefit the individual $(\mathrm{Li}$, Eschenauer, \& Persaud, 2018; Wilson, Sheehan, Palk, \& Watson, 2016), when more global issues impact or stifle the individual's ability to enact change, the highly-efficacious may feel 
more repressed, frustrated, and dissatisfied.

\section{Rethinking Gender}

This study's proposed H6, which hypothesized that a combination of high levels of femininity with lower levels of masculinity would be dissatisfying, was based on extensive findings from Bem during the 1970s and 1980s. However, counter to the relationship proposed in H6, a positive relationship between femininity scores and life satisfaction was found in this data. Thus, this finding indicates that while the Bem scales are still useful when employed as originally intended, Bem's hypotheses about societal appreciation for and reactions to feminine styles of communication may be outdated. More researchers should collect data using Bem measures to see if the trends suggested in this study hold in society at large, thereby updating researcher understandings of the impacts of gender roles from Bem's 1981 findings to modernity.

Bem further hypothesized that androgynous individuals - those high in both masculine and feminine attributes - would be the most satisfied individuals analyzed using her scales. In order to test this claim and replicate Bem's findings, masculinity was used as a moderator in the relationship between femininity and life satisfaction (H6). In this data, the moderating effect of masculinity scores on the relationship between femininity and life satisfaction approached significance. Therefore, these results suggest that like feminine attributes, masculine attributes are good, and function positively as individuals move through life. However, masculine and feminine traits work best together, echoing Bem's work on the benefits of an androgynous lifestyle $(1974 ; 1975 ; 1976 ; 1977)$. Though this trend was not significant in this sample, this finding could be a result of the small sample size and a lack of power; collecting more data could make the moderating impact of masculinity scores on the relationship between femininity score 
and life satisfaction significant.

\section{Limitations and Future Directions}

Both the proposed personal-personal measure and the established personal-enacted and personal-relational Hecht measures did not perform well in the exploratory factor analysis (Table $2,3, \& 4)$. While the identity layers are conceptualized in the CTI literature as being "interpenetrated" (Hecht et al., 2005), the results of this study suggest that the CTI measures overlap even more than intended. As a result of the overlapping nature of the factor analysis, all findings involving the CTI measures should be interpreted with caution.

Additionally, while this survey prompted the participants to answer the personalrelational scale questions with a singular relational partner in mind, the individuals considered varied widely in regards to their relationship status with the participant (i.e. biological mother, sibling, romantic partner). Due to the variety of relationship type respondents used, the answers to the P-R questions could include unaccounted-for variability. In future, researchers who use the P-R gap scale and wish to highlight a particular relationship type should prompt participants more narrowly — by asking for them to consider the relationship with a caregiver, for example, or their best, non-family friend.

Further, while a student sample was chosen to highlight the issues inherent in identity development during emerging adulthood, this thesis — and further studies using CTI to explore gender identity—could benefit from using a more diverse sample, particularly in regard to age. Understandings of gender norms have changed wildly over the past handful of generations - for example, many American women worked outside of the home during World War II, before returning to work within the home during the 1950s, only for women to reject aspects of traditional femininity and motherhood in order to return to the workforce in the 1980s. It is quite 
possible that college-age individuals, having grown up in a millennial-era America, perceive and are affected by gender norms and expectations quite differently when compared to members of prior generations, who likely experienced a different cultural landscape and set of gendered expectations for behavior.

While the initial hypothesis was developed under the belief that efficacy would be a benefit to the negative influence of gaps on wellbeing, the data did not yield this result. It is possible that the use of a global efficacy measure was the cause of this discrepancy. In future studies which explore a potential link between identity gaps and participants' self-perceived social, relational, or conversational efficacy, researchers would benefit from the use of a more narrowly-defined scale. The Sherer, et al. (1982) global efficacy measure was used in this study due to its reliability and status as an oft-used and well-established measure in the field of communication; however, a new measure developed to specifically measure participants' selfefficacy in social situations would have been more appropriate for this study.

As the preliminary results from this study suggest, Bem's findings on the negative association with femininity do not replicate in a $21^{\text {st }}$ century, emerging adult populationhowever, this could easily be a finding idiosyncratic to this particular sample, and may not hold in different age groups, or in more age-diverse samples. Implementing an Amazon MTurk population would help generate a more diverse population, as well as increase sample size, thereby reaching significance on the moderating effect of masculinity on the relationship between femininity and life satisfaction.

\section{Conclusion}

Broadly, this study sought to replicate findings published by Hecht and CTI scholars, introduce and test a new, within-gaps measure, and to replicate older Bem findings in a modern 
context. While this is just one study performed within a small population, results indicate that the established Hecht scales do work as hypothesized. More specifically, this study employed CTI measures in the exploration of gender identity development, and the resulting manifestation of gaps within individuals' layers of identity. Gender is a construct not studied extensively in literature employing CTI scales; this study indicates that gender could be a useful, fruitful, and important aspect of identity development to study through a CTI lens. Further, the success of the proposed personal-personal measure in these data suggests that more specific CTI gap measures can and should be developed—particularly within-gap measures, which are relatively new concepts in the CTI literature (Colaner, Halliwell, \& Guignon, 2014). Finally, results of this study indicate that an androgynous gender identity, as proposed by Bem, is still a highly satisfying identity to possess; however, the dissatisfaction Bem found in relation to highlyfeminine participants in the 1970s and 1980s appears to no longer exist in the emerging adult population of the 2010s. Therefore, this study suggests that some of Bem's findings considered to be universal in the literature on gender and sex roles should be retested in modern studies on gender identity. 


\section{References}

Adams, C. (2017, March 24). The gender identity terms you need to know. Retrieved February 09, 2018, from https://www.cbsnews.com/news/transgender-gender-identity-termsglossary

Beckner, B. N., \& Record, R. A. (2016). Navigating the thin-ideal in an athletic world: Influence of coach communication on female athletes' body image and health choices. Health Communication, 31, 364-373. doi:10.1080/10410236.2014.957998

Bem, S. L. (1974). The measurement of psychological androgyny. Journal of Consulting and Clinical Psychology, 42, 155-162. doi:10.1037/h0036215

Bem, S. L., \& Lewis, S. A. (1975). Sex role adaptability: One consequence of psychological androgyny. Journal of Personality and Social Psychology, 31, 634-643. doi: $10.1037 / \mathrm{h} 0077098$

Bem, S. L. (1977). On the utility of alternative procedures for assessing psychological androgyny. Journal of Consulting and Clinical Psychology, 45, 196-205. doi:10.1037/0022-006X.45.2.196

Bem, S. L. (1981). Bem Sex-Role Inventory: Professional manual. Palo Alto, CA: Consulting Psychologists Press.

Bem, S. L., Martyna, W., \& Watson, C. (1976). Sex typing and androgyny: Further explorations of the expressive domain. Journal of Personality and Social Psychology, 34, 1016-1023. doi:10.1037/0022-3514.34.5.1016

Berryman-Fink, C., Bing, J., Cameron, D., Sheldon, A., \& Taylor, A. (2008). Blogging about feminist interdisciplinarity in the study of communication, language, and gender. Women \& Language, 31, 26-35. 
Bildungsroman. (n.d.). Retrieved February 16, 2018, from https://www.merriamwebster.com/dictionary/bildungsroman

Bittner, A., \& Goodyear-Grant, E. (2017). Digging deeper into the gender gap: Gender salience as a moderating factor in political attitudes. Canadian Journal of Political Science, 50, 559-578. doi:10.1017/s0008423917000270

Brooks, C. F., \& Pitts, M. J. (2016). Communication and identity management in a globallyconnected classroom: An online international and intercultural learning experience. Journal of International \& Intercultural Communication, 9, 52-68. doi:10.1080/17513057.2016.1120849

Brontë, Charlotte (2008). Jane Eyre. Radford, VA: Wilder Publications.

Butler, J. P. (1990). Gender trouble: Feminism and the subversion of identity (1st ed.). New York, NY: Routledge.

Campbell, T., Gillaspy, J. A., Jr., \& Thompson, B. (1997). The factor structure of the Bem SexRole Inventory (BSRI): Confirmatory analysis of long and short forms. Educational and Psychological Measurement, 57, 118-124. doi:10.1177/0013164497057001008

Colaner, C. W., Halliwell, D., \& Guignon, P. (2014). "What do you say to your mother when your mother's standing beside you?" Birth and adoptive family contributions to adoptive identity via relational identity and relational-relational identity gaps. Communication Monographs, 81, 469-494. doi:10.1080/03637751.2014.955808

Colaner, C. W., \& Rittenour, C. E. (2015). "Feminism begins at home": The influence of mother gender socialization on daughter career and motherhood aspirations as channeled through daughter feminist identification. Communication Quarterly, 63, 81-98. doi:10.1080/01463373.2014.965839 
Compton, C. A. (2016). Managing mixed messages: Sexual identity management in a changing U.S. workplace. Management Communication Quarterly, 30, 415-440. doi: $10.1177 / 0893318916641215$

Costello, A. B., \& Osborne, J. W. (2005). Best practices in exploratory factor analysis: Four recommendations for getting the most from your analysis. Practical Assessment, Research \& Evaluation, 10, 1-9. doi:10.4135/9781412995627.d8

de Beauvoir, S. (2013). The second sex: Introduction. In C. R. McCann \& S. Kim (Eds.), Feminist theory reader: Local and global perspectives (3rd ed., pp. 40-48). New York, NY: Routledge. (Original work published 1952)

Diener, E., Emmons, R. A., Larsen, R. J., \& Griffin, S. (1985). The satisfaction with life scale. Journal of Personality Assessment, 49, 71-75. doi:10.1207/s15327752jpa4901_13

Gender and Sexuality: Beyond He or She TIME Cover Story. (n.d.). Retrieved February 09, 2018, from http://time.com/4703309/gender-sexuality-changing/

Hayes, Andrew F. (2013). Introduction to mediation, moderation, and conditional process analysis: A regression-based approach. New York, NY: Guilford Press.

Hecht, M. L., Faulkner, S. L., Meyer, C., Niles, T., Golden, D., \& Cutler, M. (2002). Looking through Northern Exposure at Jewish American identity and the communication theory of identity. Journal of Communication, 52, 852-869.

doi:10.1111/j.1460-2466.2002.tb02577.x

Hecht, M. L., Warren, J. R., Jung, E., \& Krieger, J. L (2005). The communication theory of identity: Development, theoretical perspective, and future directions. In W. B. Gudykunst (Ed.), Theorizing about intercultural communication (pp. 257-278). Thousand Oaks, CA: Sage. 
Huston, T. L., McHale, S. M., \& Crouter, A. C. (1986). When the homeymoon's over: Changes in the marital relationship over the first year. In R. GIlmour \& S. Duck (Eds.), The emerging field of personal relationships (pp. 109-132). Hillsdale, NJ: Lawrence Erlbaum.

Johnson, H. D., Mcnair, R., Vojick, A., Congdon, D., Monacelli, J., \& Lamont, J. (2006). Categorical and continuous measurement of sex-role orientation: Differences in associations with young adults' reports of well-being. Social Behavior and Personality: An International Journal, 34, 59-76. doi:10.2224/sbp.2006.34.1.59

Jung, E., \& Hecht, M. L. (2004). Elaborating the communication theory of identity: Identity gaps and communication outcomes. Communication Quarterly, 52, 265-283. doi.org/10.1080/01463370409370197

Kennedy-Lightsey, C. D., Martin, M. M., Labelle, S., \& Weber, K. (2015). Attachment, identity gaps, and communication and relational outcomes in marital couples' public performances. Journal of Family Communication, 15, 232-248. doi: $10.1080 / 15267431.2015 .1043430$

Letzter-Pouw, S. E., Shrira, A., Ben-Ezra, M., \& Palgi, Y. (2014). Trauma transmission through perceived parental burden among Holocaust survivors' offspring and grandchildren. Psychological Trauma: Theory, Research, Practice, and Policy, 6, 420-429.

Li, M., Eschenauer, R., \& Persaud, V. (2018). Between avoidance and problem solving: Resilience, self-efficacy, and social support seeking. Journal of Counseling \& Development, 96, 132-143. doi:10.1002/jcad.12187

Lipińska-Grobelny, A. (2011). Effects of gender role on personal resources and coping with stress. International Journal of Occupational Medicine and Environmental Health, 24. doi:10.2478/s13382-011-0002-6 
Maeda, E., \& Hecht, M. L. (2012). Identity search: Interpersonal relationships and relational identities of always-single Japanese women over time. Western Journal of Communication, 76, 44-64. doi:10.1080/10570314.2012.637539

Martin, M. M. \& Anderson, C. M. (1993) Psychological and biological differences in touch avoidance. Communication Research Reports, 10, 141-147. doi:10.1080/08824099309359927

Richmond, V. P., \& Martin, M. M. (1998). Sociocommunicative style and sociocommunicative orientation. In J. C. McCroskey et al. (Eds.) Communication and personality: Trait perspectives (pp. 133-148). New York, NY: Hampton Press.

Mokgatlhe B. P., \& Schoeman, J. B. (1998). Predictors of satisfaction with life: The role of racial identity, collective self-esteem and gender-role attitudes. South African Journal of Psychology, 28, 28-35. doi.10.1177/008124639802800105

Medved, C. E., Brogan, S. M., Mcclanahan, A. M., Morris, J. F., \& Shepherd, G. J. (2006). Family and work socializing communication: Messages, gender, and ideological implications. Journal of Family Communication, 6, 161-180. doi:10.1207/s15327698jfc0603_1

Nuru, A. K. (2014). Between layers: Understanding the communicative negotiation of conflicting identities by transgender individuals. Communication Studies, 65, 281-297. doi:10.1080/10510974.2013.833527

Palgi, Y., Shrira, A., \& Ben-Ezra, M. (2015). Family involvement and Holocaust salience among offspring and grandchildren of Holocaust survivors. Journal of Intergenerational Relationships, 13, 6-21. doi:10.1080/15350770.2015.992902

Peer, E., Vosgerau, J., \& Acquisti, A. (2013). Reputation as a sufficient condition for data quality 
on Amazon Mechanical Turk. Behavior Research Methods, 46, 1023-1031.

doi:10.3758/s13428-013-0434-y

Richmond, V. P., \& McCroskey, J. C. (1990). Reliability and separation of factors on the assertiveness-responsiveness measure. Psychological Reports, 67, 449-450. doi:10.2466/pr0.67.6.449-450

Salinger, J. D. (1951). The Catcher in the Rye. Boston, MA: Little, Brown.

Savin-Williams, R. C. (1998). The disclosure to families of same-sex attractions by lesbian, gay, and bisexual youths. Journal of Research on Adolescence, 8, 49-68. doi:10.1207/s15327795jra0801_3

Sherer, M., Maddux, J., Mercandante, B., Prentice-Dunn, S., Jacobs, B. \& Rogers, R. W. (1982). The self-efficacy scale: Construction and validation. Psychological Reports. 51, 663-671. doi:10.2466/pr0.1982.51.2.663.

Stoller, R. J. (1984). Biological substrates of sexual behavior. In Sex and gender: The development of masculinity and femininity (3rd ed., pp. 3-16). London: Karnac.

Stone, A. L. (2013). Flexible queers, serious bodies: Transgender inclusion in queer spaces. Journal of Homosexuality, 60, 1647-1665, doi:10.1080/00918369.2013.834209

Urban, E. L., \& Orbe, M. P. (2010). Identity gaps of contemporary U.S. immigrants: Acknowledging divergent communicative experiences. Communication Studies, 61, 304320. doi:10.1080/10510971003757147

Wadsworth, B. C., Hecht, M. L., \& Jung, E. (2008). The role of identity gaps, discrimination, and acculturation in international students' educational satisfaction in American classrooms. Communication Education, 57, 64-87. doi:10.1080/03634520701668407

Wagner, P. E. (2017). Bulking up (identities): A communication framework for male fitness 
identity. Communication Quarterly, 65, 580-602. doi:10.1080/01463373.2017.1321027

Wagner, P. E., Kunkel, A., \& Compton, B. L. (2016). (Trans)lating identity: Exploring discursive strategies for navigating the tensions of identity gaps. Communication Quarterly, 64, 251-272. doi:10.1080/01463373.2015.1103286

Wilson, H., Sheehan, M., Palk, G., \& Watson, A. (2016). Self-efficacy, planning, and drink driving: Applying the health action process approach. Health Psychology, 35, 695-703. doi: $10.1037 /$ hea0000358

Wittig, M. (2013). One is not born a woman. In C. R. McCann \& S. Kim (Eds.), Feminist theory reader: Local and global perspectives (3rd ed., pp. 246-251). New York, NY: Routledge. (Original work published 1981)

Wooten, A. G., \& McCroskey, J. C. (1996). Student trust of teacher as a function of sociocommunicative style of teacher and socio-communicative orientation of student. Communication Research Reports, 13, 94-100. doi:10.1080/08824099609362075

Yang, Z. J. (2015). Altruism during Ebola: Risk perception, issue salience, cultural cognition, and information processing. Risk Analysis, 36, 1079-1089. doi:10.1111/risa.12526 


\section{Appendix A}

Table 1: Pearson correlation matrix of all study variables, including coefficient $r$, sample size $n$, and $p$-value.

\begin{tabular}{|c|c|c|c|c|c|c|c|c|c|c|}
\hline & $\begin{array}{l}\text { Personal- } \\
\text { Personal }\end{array}$ & $\begin{array}{l}\text { Personal- } \\
\text { Enacted }\end{array}$ & $\begin{array}{l}\text { Personal- } \\
\text { Relational }\end{array}$ & Masculinity & Femininity & $\begin{array}{l}\text { Gender } \\
\text { Salience }\end{array}$ & $\begin{array}{c}\text { Gender } \\
\text { Salience } \\
\text { Slider }\end{array}$ & $\begin{array}{c}\text { Relational } \\
\text { Satisfaction }\end{array}$ & $\begin{array}{c}\text { Life } \\
\text { Satisfaction }\end{array}$ & Efficacy \\
\hline $\begin{array}{l}\text { Personal- } \\
\text { Personal }\end{array}$ & -- & & & & & & & & & \\
\hline $\begin{array}{l}\text { Personal- } \\
\text { Enacted }\end{array}$ & $\begin{array}{c}r=.704 \\
p<.001 \\
n=232\end{array}$ & -- & & & & & & & & \\
\hline $\begin{array}{l}\text { Personal- } \\
\text { Relational }\end{array}$ & $\begin{array}{c}r=.590 \\
p<.001 \\
n=232\end{array}$ & $\begin{array}{l}r=.699 \\
p<.001 \\
n=232\end{array}$ & -- & & & & & & & \\
\hline Masculinity & $\begin{array}{c}r=-.062 \\
p=.346 \\
n=236\end{array}$ & $\begin{array}{c}r=-.158 \\
p=.250 \\
n=232\end{array}$ & $\begin{array}{c}r=-.076 \\
p=.250 \\
n=232\end{array}$ & -- & & & & & & \\
\hline Femininity & $\begin{array}{c}r=-.268 \\
p<.001 \\
n=236\end{array}$ & $\begin{array}{c}r=-.345 \\
p<.001 \\
n=232\end{array}$ & $\begin{array}{c}r=-.281 \\
p<.001 \\
n=232\end{array}$ & $\begin{array}{c}r=.091 \\
p=.162 \\
n=238\end{array}$ & -- & & & & & \\
\hline $\begin{array}{l}\text { Gender } \\
\text { Salience }\end{array}$ & $\begin{array}{c}r=.170 \\
p=.009 \\
n=234\end{array}$ & $\begin{array}{c}r=.132 \\
p=.046 \\
n=230\end{array}$ & $\begin{array}{c}r=.095 \\
p=.150 \\
n=230\end{array}$ & $\begin{array}{c}r=.045 \\
p=.492 \\
n=236\end{array}$ & $\begin{array}{c}r=.153 \\
p=.019 \\
n=236\end{array}$ & -- & & & & \\
\hline $\begin{array}{l}\text { Gender } \\
\text { Salience } \\
\text { Slider }\end{array}$ & $\begin{array}{c}r=.120 \\
p=.070 \\
n=229\end{array}$ & $\begin{array}{c}r=.013 \\
p=.849 \\
n=225\end{array}$ & $\begin{array}{c}r=.038 \\
p=.575 \\
n=225\end{array}$ & $\begin{array}{c}r=.025 \\
p=.700 \\
n=231\end{array}$ & $\begin{array}{c}r=.057 \\
p=.392 \\
n=231\end{array}$ & $\begin{array}{c}r=.799 \\
p<.001 \\
n=230\end{array}$ & -- & & & \\
\hline
\end{tabular}




$\begin{array}{cccccccccc}\text { Relational } & r=-.342 & r=-.412 & r=-.537 & r=.127 & r=.282 & r=-.020 & r=-.029 & \\ \text { Satisfaction } & p<.001 & p<.001 & p<.001 & p=.052 & p<.001 & p=.767 & p=.664 & -- \\ & n=233 & n=232 & n=232 & n=233 & n=233 & n=231 & n=226 & \\ & & & & & & & & \\ \text { Life } & r=-.447 & r=-.412 & r=-.354 & r=.176 & r=.336 & r=.062 & r=-.010 & r=.390 \\ \text { Satisfaction } & p<.001 & p<.001 & p<.001 & p=.008 & p<.001 & p=.356 & p=.885 & p<.001 \\ & n=229 & n=232 & n=228 & n=229 & n=229 & n=227 & n=222 & n=229 \\ \text { Efficacy } & r=-.475 & r=-.614 & r=-.474 & r=.297 & r=.308 & r=-.024 & r=.061 & r=.395 & r=.495 \\ & p<.001 & p<.001 & p<.001 & p<.001 & p<.001 & p=.721 & p=.368 & p<.001 & p<.001 \\ & n=229 & n=228 & n=228 & n=229 & n=229 & n=227 & n=222 \quad n=229 & n=229\end{array}$


Table 2. Exploratory Factor Analysis of Communication Theory of Identity's Personal-Personal subscale, factors retained using scree tests

\begin{tabular}{|c|c|c|c|c|c|c|c|c|}
\hline Personal-Personal Subscale & $\begin{array}{c}\text { Factor } \\
1\end{array}$ & $\begin{array}{l}\text { Factor } \\
2\end{array}$ & $\begin{array}{c}\text { Factor } \\
3\end{array}$ & $\begin{array}{c}\text { Factor } \\
4\end{array}$ & $\begin{array}{c}\text { Factor } \\
5\end{array}$ & $\begin{array}{c}\text { Factor } \\
6\end{array}$ & $\begin{array}{c}\text { Factor } \\
7\end{array}$ & $\begin{array}{c}\text { Factor } \\
8\end{array}$ \\
\hline 1. I often feel that I am not living as my "true self." & .558 & & & & & & & \\
\hline 2. I hope to one day live as my most authentic self. & & & & & & & & \\
\hline 3. I feel that I am the best version of myself I can be. ${ }^{\circledR}$ & .495 & .331 & & & & & .351 & \\
\hline 4. The way I identify right now is not the person I will be forever. & .334 & & & & & & & \\
\hline 5. I am far from the person I one day hope to become. & .450 & & .391 & & & & & \\
\hline $\begin{array}{l}\text { 6. When I think of my gender identity, I think of all the ways I hope to } \\
\text { change. }\end{array}$ & .570 & & & & & & & \\
\hline 7. I am living my most authentic life. ${ }^{\circledR}$ & .503 & .434 & & & & & & \\
\hline $\begin{array}{l}\text { 8. The way I self-identify currently differs from the identity I wish to } \\
\text { have. }\end{array}$ & .700 & & & & & & & \\
\hline 9. I could be happier with my personally-held identity. & .630 & & & & & & & \\
\hline 10. I believe I have not yet reached my potential of self-actualization. & .525 & & .439 & & & & & \\
\hline 11. My gender identity will evolve as I age. & .570 & & .358 & & & & & \\
\hline 12. I have yet to become the "true" version of myself. & .572 & & .404 & & & & & \\
\hline 13. The way I self-identify currently is the identity I wish to have. ${ }^{\circledR}$ & .401 & .361 & & & & & & \\
\hline 14. I feel as through I am the best version of myself. ${ }^{\circledR}$ & .578 & .344 & & & & & & \\
\hline 15. I feel happy with my current identity. ${ }^{\circledR}$ & .663 & & & & & & & \\
\hline
\end{tabular}

Note. Only those eigen-values above .32 are recorded. 
Table 3. Exploratory Factor Analysis of Communication Theory of Identity's Personal-Enacted subscale, factors retained using scree test

\begin{tabular}{|c|c|c|c|c|c|c|c|c|}
\hline Personal-Enacted Subscale & $\begin{array}{c}\text { Factor } \\
1\end{array}$ & $\begin{array}{c}\text { Factor } \\
2\end{array}$ & $\begin{array}{l}\text { Factor } \\
\quad 3\end{array}$ & $\begin{array}{c}\text { Factor } \\
4\end{array}$ & $\begin{array}{c}\text { Factor } \\
5\end{array}$ & $\begin{array}{l}\text { Factor } \\
\quad 6\end{array}$ & $\begin{array}{c}\text { Factor } \\
7\end{array}$ & $\begin{array}{c}\text { Factor } \\
8\end{array}$ \\
\hline $\begin{array}{l}\text { 1. When I communicate with others, they get to } \\
\text { know the "real me." } ₫\end{array}$ & .380 & .504 & & & & & & \\
\hline $\begin{array}{l}\text { 2. I feel that I can communicate in a way that is } \\
\text { consistent with who I really am. }{ }^{\circledR}\end{array}$ & .561 & .478 & & & & & & \\
\hline $\begin{array}{l}\text { 3. I feel that I can be myself when } \\
\text { communicating with other people. } \AA\end{array}$ & .595 & .461 & & & & & & \\
\hline $\begin{array}{l}\text { 4. I express my gender identity in a certain way } \\
\text { that is not the real me. }\end{array}$ & .769 & & & & & -.338 & & \\
\hline $\begin{array}{l}\text { 5. I do not reveal important aspects of myself in } \\
\text { communication with others. }\end{array}$ & .491 & & & & & & & \\
\hline $\begin{array}{l}\text { 6. When communicating with others, I often } \\
\text { lose sense of who I am. }\end{array}$ & .792 & & & & & & & \\
\hline $\begin{array}{l}\text { 7. I do not express the real me when I think it is } \\
\text { different from others' expectations. }\end{array}$ & .707 & & & -.407 & & & & \\
\hline $\begin{array}{l}\text { 8. I sometimes mislead other people about who } \\
\text { I really am. }\end{array}$ & .757 & & & & & & & \\
\hline $\begin{array}{l}\text { 9. There is a difference between the real me and } \\
\text { the impression I give other people around me. }\end{array}$ & .745 & & & -.332 & & & & \\
\hline $\begin{array}{l}\text { 10. I speak truthfully about my gender identity. } \\
\mathbb{B}\end{array}$ & .476 & & & .461 & & & & \\
\hline 11. I freely express the real me. ${ }^{\circledR}$ & .530 & .368 & & & & & & \\
\hline
\end{tabular}

Note. Only those eigen-values above .32 are recorded. 
Table 4. Exploratory Factor Analysis of Communication Theory of Identity's Personal-Relational subscale, factors retained using scree test

\begin{tabular}{|c|c|c|c|c|c|c|c|c|}
\hline Personal-Relational Subscale & $\begin{array}{c}\text { Factor } \\
1\end{array}$ & $\begin{array}{c}\text { Factor } \\
2\end{array}$ & $\begin{array}{c}\text { Factor } \\
3\end{array}$ & $\begin{array}{c}\text { Factor } \\
4\end{array}$ & $\begin{array}{c}\text { Factor } \\
5\end{array}$ & $\begin{array}{c}\text { Factor } \\
6\end{array}$ & $\begin{array}{c}\text { Factor } \\
7\end{array}$ & $\begin{array}{c}\text { Factor } \\
8\end{array}$ \\
\hline 1. I feel this person sees me as I see myself. $\left({ }^{\circledR}\right.$ & .554 & .374 & & & & & & \\
\hline $\begin{array}{l}\text { 2. I am different from the way that this person } \\
\text { sees me. }\end{array}$ & .645 & & & & & & & \\
\hline 3. I agree with how this person describes me. ${ }^{\circledR}$ & .555 & .325 & & & & & & \\
\hline $\begin{array}{l}\text { 4. I feel that this person has wrong images of } \\
\text { my gender identity. }\end{array}$ & .655 & & & & & & & \\
\hline $\begin{array}{l}\text { 5. I feel that the person I'm thinking about has } \\
\text { correct information about me. } \mathbb{R}\end{array}$ & .393 & .359 & & & & & & \\
\hline $\begin{array}{l}\text { 6. I feel that this person portrays my gender } \\
\text { identity not based on information provided } \\
\text { by myself but information from other } \\
\text { sources. }\end{array}$ & .453 & & & & & & & \\
\hline 7. I feel that this person stereotypes me. & .658 & & & & & & & \\
\hline $\begin{array}{l}\text { 8. I feel that this person does not realize that I } \\
\text { have been changing and still portrays me } \\
\text { based on my past images. }\end{array}$ & 679 & & -.427 & & & & & \\
\hline $\begin{array}{l}\text { 9. I feel that this person knows who I used to be } \\
\text { when they portray me. }{ }^{\circledR}\end{array}$ & -.316 & & & & & & & \\
\hline $\begin{array}{l}\text { 10. When the person I'm thinking of talks about } \\
\text { me, I often wonder if they're talking about } \\
\text { me or someone else. }\end{array}$ & .593 & & & & & & & \\
\hline $\begin{array}{l}\text { 11. I feel there is no difference between who I } \\
\text { think I am and who this person thinks I am. } \\
\mathbb{R}\end{array}$ & .373 & .343 & & & & & & \\
\hline
\end{tabular}

Note. Only those eigen-values above .32 are recorded. 
Table 5. For all variables, difference between participants who reported caring and those who reported not caring about gender or gender-related issues.

\begin{tabular}{|c|c|c|c|c|}
\hline & $t$ & $\begin{array}{l}\text { Care about gender or gender- } \\
\text { related issues }(n=138)\end{array}$ & $\begin{array}{l}\text { Don't care about gender or } \\
\text { gender-related issues }(n=97)\end{array}$ & Significance \\
\hline $\begin{array}{l}\text { Gender Salience (3- } \\
\text { Item) }\end{array}$ & 13.46 & $\begin{array}{c}M=4.24 \\
S D=1.24\end{array}$ & $\begin{array}{l}M=2.15 \\
S D=1.12\end{array}$ & $p<.001$ \\
\hline $\begin{array}{l}\text { Gender Salience } \\
\text { (Sliding scale) }\end{array}$ & 12.59 & $\begin{array}{l}M=55.08 \\
S D=21.79\end{array}$ & $\begin{array}{l}M=21.79 \\
S D=16.28\end{array}$ & $p<.001$ \\
\hline Masculinity & .56 & $\begin{array}{l}M=4.85 \\
S D=.76\end{array}$ & $\begin{array}{l}M=4.79 \\
S D=.84\end{array}$ & $p=.58$ \\
\hline Femininity & 3.13 & $\begin{array}{l}M=5.54 \\
S D=.94\end{array}$ & $\begin{array}{l}M=5.16 \\
S D=.93\end{array}$ & $p=.002$ \\
\hline Personal-Personal Gap & .77 & $\begin{array}{c}M=2.87 \\
S D=2.76\end{array}$ & $\begin{array}{l}M=2.49 \\
S D=1.00\end{array}$ & $p=.44$ \\
\hline Personal-Enacted Gap & -.17 & $\begin{array}{c}M=2.49 \\
S D=1.09\end{array}$ & $\begin{array}{l}M=2.52 \\
S D=1.10\end{array}$ & $p=.86$ \\
\hline Personal-Relational Gap & -1.64 & $\begin{array}{c}M=2.01 \\
S D=2.25\end{array}$ & $\begin{array}{c}M=1.02 \\
S D=1.19\end{array}$ & $p=.10$ \\
\hline Life Satisfaction & -.05 & $\begin{array}{l}M=5.25 \\
S D=1.15\end{array}$ & $\begin{array}{l}M=5.26 \\
S D=1.09\end{array}$ & $p=.96$ \\
\hline Relational Satisfaction & .92 & $\begin{array}{l}M=6.26 \\
S D=.96\end{array}$ & $\begin{array}{l}M=6.14 \\
S D=1.02\end{array}$ & $p=.36$ \\
\hline Efficacy & 1.68 & $\begin{array}{l}M=4.93 \\
S D=.93\end{array}$ & $\begin{array}{l}M=4.73 \\
S D=.80\end{array}$ & $p=.10$ \\
\hline
\end{tabular}


Table 6. Partial correlation matrix of personal-personal gap, personal-enacted gap, personal-relational gap, relational satisfaction, and life satisfaction, using the 3 -item gender salience measure as a control variable.

\begin{tabular}{|c|c|c|c|c|c|c|}
\hline \multirow{6}{*}{$\begin{array}{l}\text { Control Variable: } \\
\text { Gender Salience }\end{array}$} & & $\begin{array}{l}\text { Personal- } \\
\text { Personal }\end{array}$ & $\begin{array}{l}\text { Personal- } \\
\text { Enacted }\end{array}$ & $\begin{array}{l}\text { Personal- } \\
\text { Relational }\end{array}$ & $\begin{array}{l}\text { Relational } \\
\text { Satisfaction }\end{array}$ & $\begin{array}{c}\text { Life } \\
\text { Satisfaction }\end{array}$ \\
\hline & $\begin{array}{l}\text { Personal- } \\
\text { Personal }\end{array}$ & -- & & & & \\
\hline & $\begin{array}{l}\text { Personal- } \\
\text { Enacted }\end{array}$ & $\begin{array}{c}r=.70 \\
p<.001 \\
d f=223\end{array}$ & -- & & & \\
\hline & $\begin{array}{l}\text { Personal- } \\
\text { Relational }\end{array}$ & $\begin{array}{c}r=.58 \\
p<.001 \\
d f=223\end{array}$ & $\begin{array}{c}r=.70 \\
p<.001 \\
d f=223\end{array}$ & -- & & \\
\hline & $\begin{array}{l}\text { Relational } \\
\text { Satisfaction }\end{array}$ & $\begin{array}{c}r=-.32 \\
p<.001 \\
d f=223\end{array}$ & $\begin{array}{c}r=-.41 \\
p<.001 \\
d f=223\end{array}$ & $\begin{array}{c}r=-.53 \\
p<.001 \\
d f=223\end{array}$ & -- & \\
\hline & $\begin{array}{c}\text { Life } \\
\text { Satisfaction }\end{array}$ & $\begin{array}{l}r=-.46 \\
p<.001 \\
d f=223\end{array}$ & $\begin{array}{l}r=-.43 \\
p<.001 \\
d f=223\end{array}$ & $\begin{array}{l}r=-.35 \\
p<.001 \\
d f=223\end{array}$ & $\begin{array}{c}r=.36 \\
p<.001 \\
d f=223\end{array}$ & -- \\
\hline
\end{tabular}


Figure 1. Efficacy moderating the relationship between life satisfaction and personal-relational gap, for low (score of 3.97 on 7-point scale), medium (score of 4.85 on 7-point scale), and high (score of 5.72 on 7-point scale) levels of efficacy.

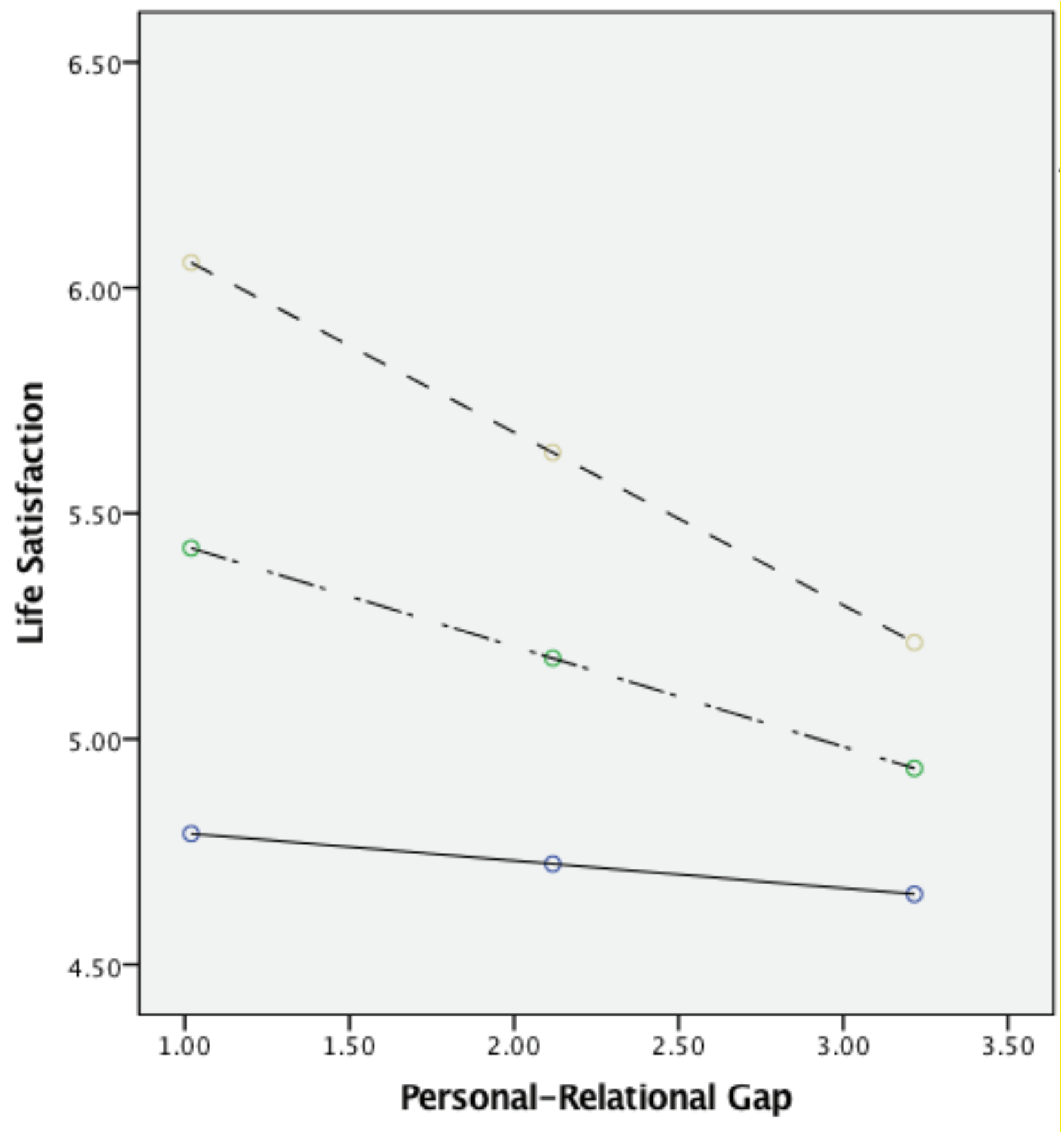


Figure 2. Masculinity moderating the relationship between femininity and life satisfaction for low (score of 4.03 on 7-point scale), medium (score of 4.82 on 7-point scale), and high (score of 5.60 on 7-point scale) levels of masculinity

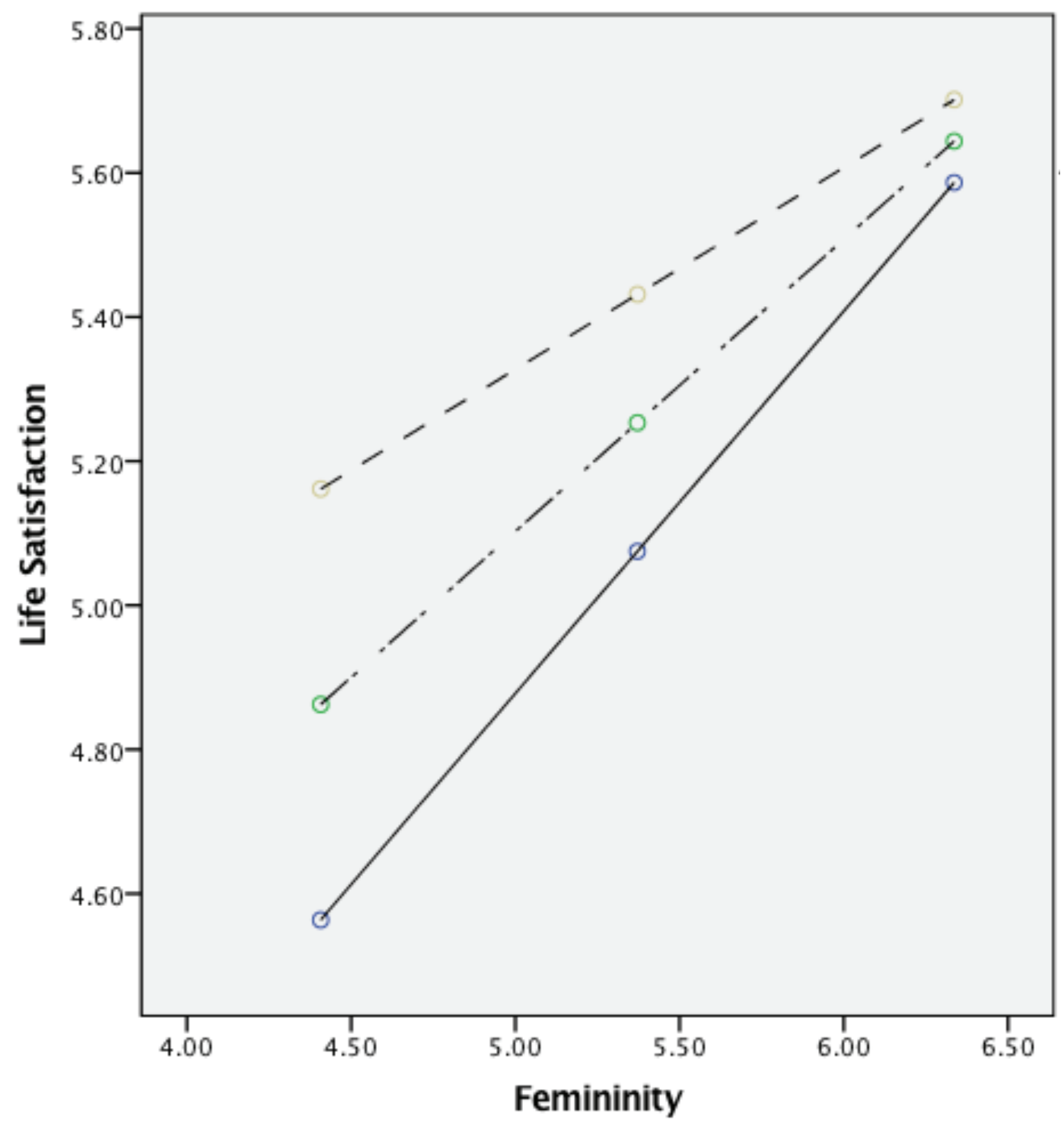




\section{Appendix B}

You are invited to participate in a study about gender and communication. We want to learn about how your identity coincides with how you talk to people and how you feel about yourself.

You must be 18 years of age or older to participate.

Your involvement in this project will be anonymous, and we will not ask any information that would lead back to your identity as a participant. Your participation is completely voluntary, and your participation or nonparticipation will be of no penalty to you in the department, university, or with any of your instructors. You may skip any question that you do not wish to answer, and you may discontinue at any time.

West Virginia University's Institutional Review Board acknowledgement of this project (\#1803039308) is on file.

The questionnaire will take you approximately 30 minutes to complete, and you may be eligible to receive extra credit points in a Communication Studies course upon completion of this survey. Please make sure to print or screen-capture your unique participant code that generates at the end of the survey, and consult your syllabus or instructor for more details.

This survey will be available for completion until April $\mathbf{5}^{\text {th }}, \mathbf{2 0 1 8}$, or until the maximum number of participants are reached.

This project is being conducted by Janelle Vickers (MA Student), and overseen by Dr. Christine E. Rittenour (Associate Professor), both of whom are in the Department of Communication Studies at WVU. Should you have any questions about this letter or the research project, please feel free to contact Janelle Vickers at jpvickers@mix.wvu.edu.

Thank you for your interest in this study!

You may access the survey here: https://wvu.qualtrics.com/jfe/form/SV_3CbKxyPz5DIBgJ7 
Hello! I am Janelle Vickers, Masters Student, Communication Studies. Dr. Rittenour and I are conducting a study about gender and communication. You will have to be older than 18 years old to participate in this study. It has been approved by WVU's Institutional Review Board (\#1803039308). Participation in this study is voluntary. Your participation includes completing an online questionnaire. You may earn extra credit in a Communication Studies course in exchange for your participation in this study. You can stop at any point without fear of penalty. There are no risks associated with participation in this study.

Please see the flier for your anonymous survey link! Thank you for your time. 
Cover

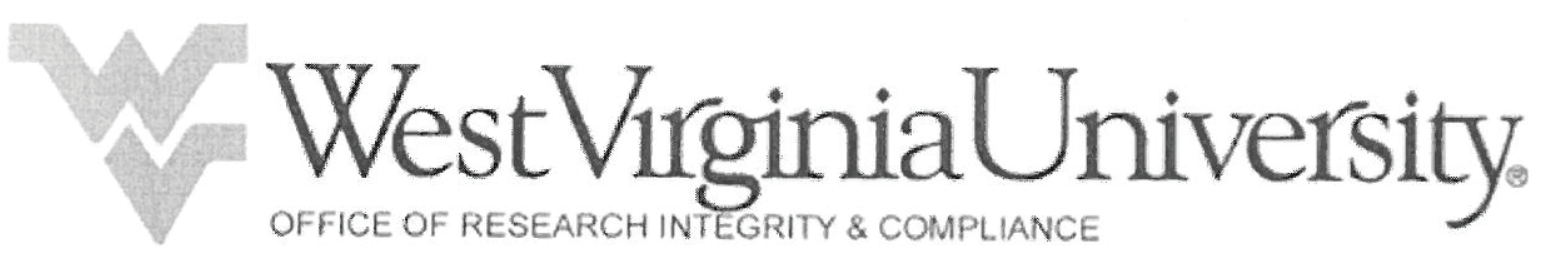

Dear Participant,

This letter is a request for you to take part in research assessing gender and communication. We want to learn about how your identity coincides with how you talk to people and how you feel about yourself. This project is being conducted by Janelle Vickers (MA Student), and overseen by Dr. Christine E. Rittenour (Associate Professor), both of whom are in the Department of Communication Studies at WVU. Institutional Review Board approval for this project (\#1803039308) is on file. Your participation in this project is greatly appreciated, and it will take you approximately 20 minutes to fill out this questionnaire. You also have the opportunity to receive extra credit points in a Communication Studies course upon completion of this survey.

Your involvement in this project will be anonymous. All data will be reported in the aggregate. You must be 18 years of age or older to participate. We will not ask any information that should lead back to your identity as a participant. Your participation is completely voluntary. You may skip any question that you do not wish to answer, and you may discontinue at any time. West Virginia University's Institutional Review Board acknowledgement of this project is on file.

We hope that you will participate in this research project. Thank you very much for your time. Should you have any questions about this letter or the research project, please feel free to contact Janelle Vickers at jpvickers@mix.wvu.edu.

Thank you for your time and help with this project.

Sincerely, 


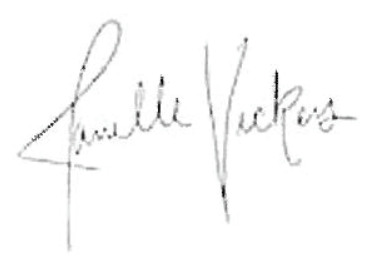

Janelle Vickers

Department of Communication Studies

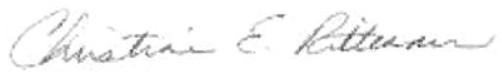

Christine E. Rittenour, Ph.D.

Department of Communication Studies

I have read the information above and ...

Agree, and would like to continue the survey.

Disagree, and would like to exit the survey.

\section{BSRI}

Indicate on the scale below (ranging from "almost never true" to "almost always true") how well each of the following 30 items describes you.

Almost

Never

True
Usually Rarely

Not True True
Occasionally

True
Often True
Almost Usually Always True True

Has leadership abilities

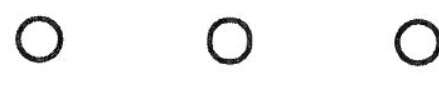

Gentle

Adaptable

$\begin{array}{lll}0 & 0 & 0 \\ 0 & 0 & 0\end{array}$

Almost

Never

True
0

$0 \quad 0$

O
O

0

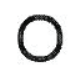

O

$\mathrm{O}$
O

$\mathrm{O}$

0
$\mathrm{O}$

$\mathrm{O}$

$\mathrm{O}$

Almost

Always

True

Occasionally True

Often

Usually

True

ก 
Tender

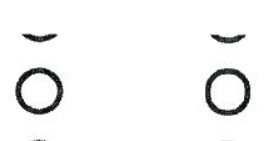

Qualtrics Survey Software

Conscientious

$0 \quad 0$

$\overline{0}$

○

○

O

Dominant

Compassionate

0

0

0

0

0

Conceited

00

$\mathrm{O}$

0

0

0

O

O

O

Strong personality

00

0

0

00

Warm

O

O

O

O

O

Conventional

00

0

O

0

O

Forceful

Sympathetic

00

0

0

0

0

0

O

O

O

Jealous

Aggressive

Sensitive to the

needs of others

00

0

0

0

0

Moody

Willing to take a stand

00

0

$\mathrm{O}$

0

0

O 0

0

0

O

O

O 0

O

O

O $\mathrm{O}$

0

0

O 0

0

0

0

0

Eager to soothe hurt feelings

O $\mathrm{O}$

Reliable

Independent

Understanding

Secretive

000

$\mathrm{O}$

$\mathrm{O}$

O 0

0

0

0

0

0

Defends own beliefs

Affectionate

Tactful

O 00

O

O $\mathrm{O}$

O

0

0

O

0

$0 \quad 0 \quad 0$

0

0

0

O 0 O

O

O

O

O

O

O

O

$0 \quad 0$

$\mathrm{O}$

0

0

O 00

O

O

O

O 0

O

O

O

Willing to take risks

0

0

0

0

$\mathrm{O}$

Loves children

O

0

O

0

0

Truthful

$0 \quad 0$

0

O

0

O

\section{Block 9}

The following questions will assess some of your opinions on gender and gender-related issues. 
Do you care about gender or gender-related issues?

Yes

No

Please indicate your level of agreement with the following statements by selecting the appropriate, corresponding bubble on the scale below. Please be open and honest in your responding.

I frequently think about gender.

I am interested in gender more than most of the people I know.

Gender-related issues are important to me.
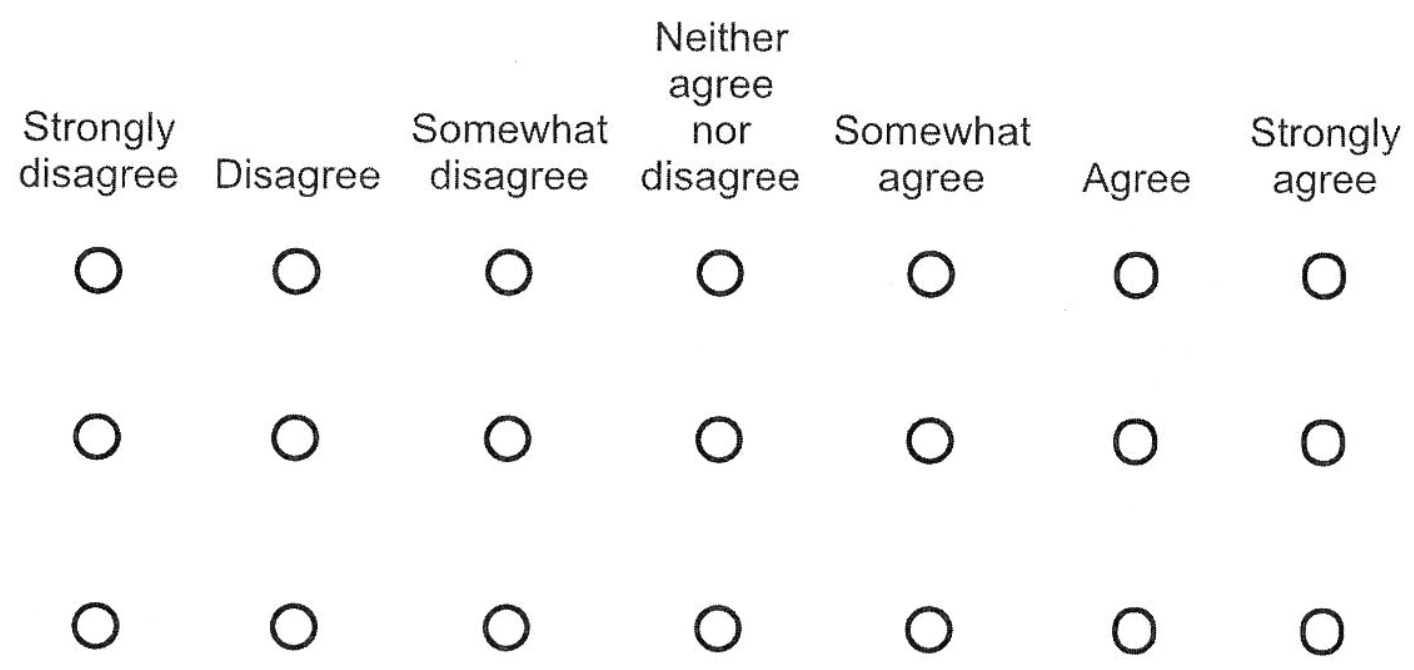

Use the sliders below to respond based on your your intensity about these prompts.

How much do you care about gender or gender-related issues?

(On the slider, "0" represents "I do not care at all" and "100" represents "I care a lot".)

$\begin{array}{lllllllllll}0 & 10 & 20 & 30 & 40 & 50 & 60 & 70 & 80 & 90 & 100\end{array}$

How often do you discuss gender or gender-related issues with other people?

(On the slider, "0" represents "I never discuss gender issues with other people" and "100" represents "I discuss gender issues very frequently with other people".) 
How important do you find issues of gender identity and gender expression to be in relation to other local or national issues and world events?

(On the slider, "0" represents "I find gender issues to be completely unimportant in comparison to other issues" and "100" represents "I find gender issues to be extremely important in comparison to other issues".)

$\begin{array}{lllllllllll}0 & 10 & 20 & 30 & 40 & 50 & 60 & 70 & 80 & 90 & 100\end{array}$

\section{Matrix}

Keep thinking about your gender identity. For the following items referring to your gender identity, please indicate your level of agreement by selecting the appropriate, corresponding bubble on the scale below. Please be open and honest in your responding.

I often feel that I am not living as my "true self."

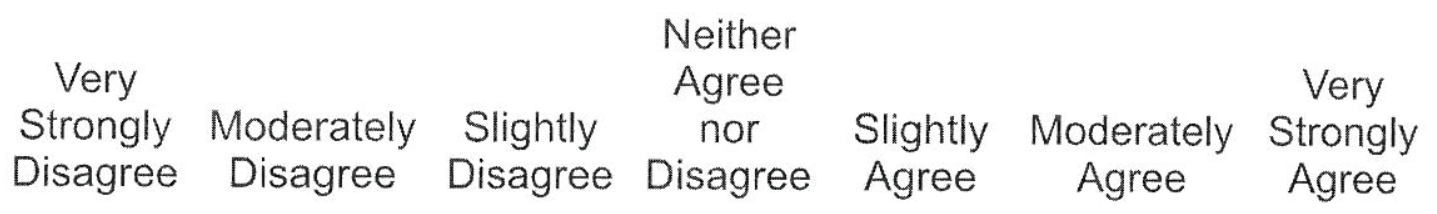

I hope to one day live as my most authentic self.
O
O
O
O
$\mathrm{O}$
O
$\mathrm{O}$
0

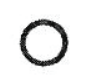
O
O
O
O
O

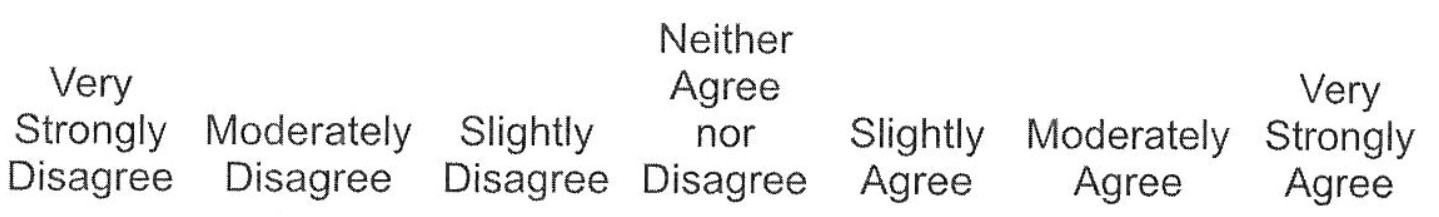

I feel that I am the best version of myself I can be.

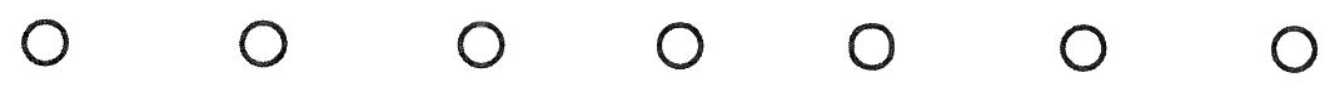


The way I identify right now is not the person I will be

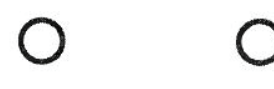

0

0

0

0

0

forever.

I am far from the person I one day hope to become.

O

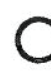

0

0

0

0

0

When I think of my gender identity, I

think of all the

ways I hope to

O

0

0

0

0

0

0

change.

I am living my most

authentic life.

O

0

0

0

0

0

The way I selfidentify currently differs from the identity I wish to

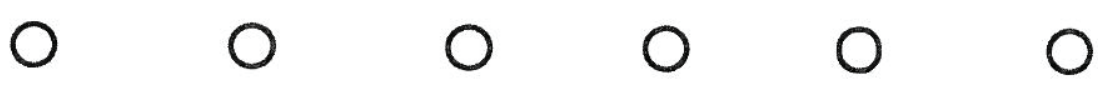

have.

I could be happier with my personallyheld identity.

$\begin{array}{llllllll}0 & 0 & 0 & 0 & 0 & 0 & 0\end{array}$

I believe I have not yet reached my potential of selfactualization.

My gender identity will evolve as I age.

O

0

0

0

0

0

I have yet to become the "true" version of myself.

$\begin{array}{lllll}0 & 0 & 0 & 0\end{array}$

0

0

The way I selfidentify currently is the identity I wish to have.

$\begin{array}{lllllllll}0 & 0 & 0 & 0 & 0 & 0\end{array}$

I feel as though I am the best version of myself.

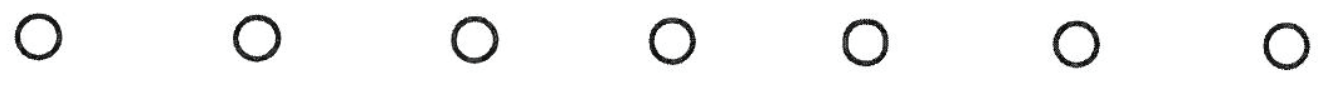

$\begin{array}{ccccccc}\begin{array}{c}\text { Very } \\ \text { Strongly }\end{array} & \text { Moderately } & \text { Slightly } & \text { Agree } & \text { nor } & \text { Slightly } & \text { Moderately } \\ \text { Disagree } & \text { Disagree } & \text { Disagree } & \text { Disagree } & \text { Agree } & \text { Agree } & \text { Agree } \\ \text { Disly } & \text { Agree } & & 0 & 0\end{array}$

I feel happy with my current identity. 


\section{Block 3}

For the following items, please indicate your level of agreement by selecting the appropriate, corresponding bubble on the scale below. Please be open and honest in your responding.

\section{When I}

communicate with others, they get to

Very
Strongly Moderately
Disagree Disagree

Neither

Slightly $\begin{gathered}\text { Agree } \\ \text { Not Slightly Moderately Strongly }\end{gathered}$

Disagree Disagree Agree Agree Agree

know the "real me."
$\mathrm{O}$
0
O
O
0
0
0

I feel that I can

communicate in a

way that is

consistent with who

I really am.

I feel that I can be

myself when

communicating

with other people.

I express my

gender identity in a certain way that is

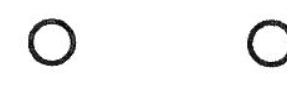

0

0

0

0

0

0

not the real me.

I do not reveal important aspects of myself in communication with others.

When communicating with others, I often lose sense of who I

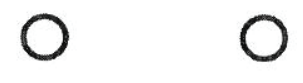

0 am.

Very

Strongly Moderately Slightly

Disagree Disagree Disagree
O

O

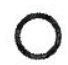

$\mathrm{O}$
Neither

Agree

Not
0

0

0

O

Disagree Agree Agree
Very Strongly

I do not express 
tne real me wnen I think it is different from others'

$\begin{array}{llllllll}0 & 0 & 0 & 0 & 0\end{array}$
expectations.

I sometimes mislead other people about who I
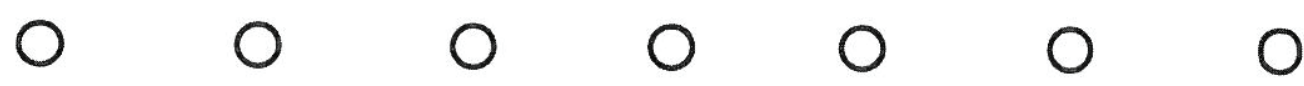
really am.

There is a difference between the real me and the impression I give

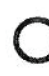

$\begin{array}{llllllll}0 & 0 & 0 & 0 & 0 & 0\end{array}$ other people about me.

I speak truthfully about my gender identity.

O

I freely express the real me.
$0 \quad 0$
O

O

O

O
O
O

O
O

O

Next, we want you to think about someone close to you. This person could be a romantic partner or a very close friend or family member. To help you keep this person in mind, please put their initials below.

The close friend or family member you are thinking about has the following initials:

Please write a few words to describe your relationship with this person (for example, "mom," "best friend," "brother," "girlfriend"). Remember to keep this person in mind when you answer the next set of questions.

For the following items, please indicate your level of agreement by selecting the appropriate, corresponding bubble on the scale below. Please be open and honest in your responding.

Neither 


Disagrée Disagree Disăgrée Disagree Ağreé Agree 'Agrěe’

I feel that this

person sees me as

$\begin{array}{llllll}0 & 0 & 0 & 0\end{array}$

O

I see myself.

I am different from

the way that this

person sees me.

O

0

0

0

0

0

0

I agree with how

this person

O

0

0

0

0

0

I feel that this

person has wrong

images of my

gender identity.

I feel that the person I'm thinking about has correct information about

0

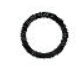

0

0

0

0

0

me.

I feel that this person portrays my gender identity not based on information provided by myself

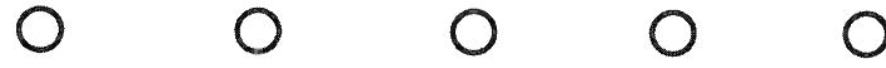

O

0

but information

from other

sources.

I feel that this

person

stereotypes me.

O

0

0

0

0

0

I feel that this

person does not

realize that I have

been changing

and still portrays

me based on my

past images.

I feel that this

person knows who I used to be when

0

0

0

0

0

0

they portray me.

Very

Strongly Moderately Slightly

Disagree Disagree
Neither

Agree

Not
Very

Slightly Moderately Strongly Agree Agree Agree

When the person 
I'm tnınkıng or talks about me, I often wonder if they talk O $\mathrm{O}$ $\mathrm{O}$

$\mathrm{O}$

$\mathrm{O}$

O $\mathrm{O}$ about me or someone else.

I feel that there is no difference between who I think I am and who this person thinks I am.

\section{Block 11}

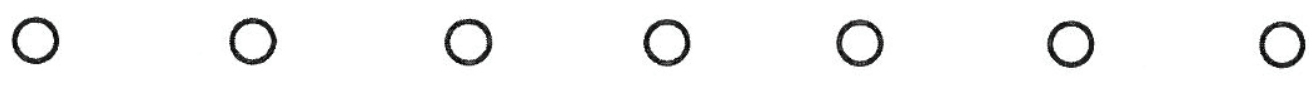

Please answer the following questions about your relationship with the person you are thinking about. Please select the bubble that most closely describes your feelings toward this person over the past month.

Miserable

Enjoyable

Hopeful

Free

Tied Down

Empty

Full

Interesting 
Rewarding

Doesn't give me much chance

Lonely Hard

All things considered, how satisfied have you been with your relationship with this specific person over the past month? (Please select one.)

$\begin{aligned} & \text { Completely } \\ & \text { dissatisfied }\end{aligned} \quad \cdot \quad+\quad$ Neutral $\quad \cdot \quad \cdot \quad \cdot \quad \cdot \quad \cdot \quad \begin{gathered}\text { Completely } \\ \text { satisfied }\end{gathered}$

\section{Block 6}

In your own words, tell us your experience with, and subsequent satisfaction or dissatisfaction with gender norms.

In your own words, describe your satisfaction or dissatisfaction with labeling certain behaviors or traits as either "masculine" or "feminine." 
In your own words, describe your satisfaction or dissatisfaction with labeling certain behaviors or traits as belonging to either (just) men or (just) women.

\section{Default Block}

Below are five statements that you may agree or disagree with. Please indicate your level of agreement by selecting the appropriate, corresponding bubble on the scale below. Please be open and honest in your responding.

\begin{tabular}{ccccc}
\multicolumn{5}{c}{$\begin{array}{c}\text { Neither } \\
\text { agree }\end{array}$} \\
Strongly & Somewhat & nor & Somewhat \\
Disagree Disagree & disagree & disagree & agree & Sgree $\begin{array}{c}\text { Strongly } \\
\text { agree }\end{array}$
\end{tabular}

In most ways, my

life is close to my ideal.
$\mathrm{O}$
O
O
O
O
$\mathrm{O}$
$\mathrm{O}$

The conditions of my life are excellent.

$\begin{array}{lllllll}0 & 0 & 0 & 0 & 0 & 0 & 0 \\ 0 & 0 & 0 & 0 & 0 & 0 & 0\end{array}$

my life.

So far, I have gotten the important things I want in life.

$\begin{array}{lllllll}0 & 0 & 0 & 0 & 0 & 0 & 0\end{array}$

If I could live my life over, I would change almost nothing.

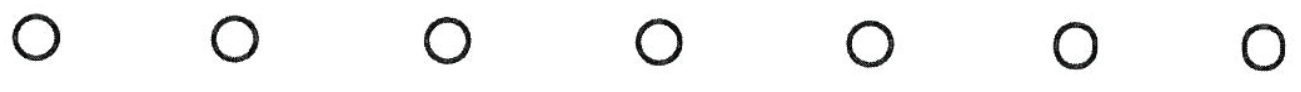

\section{Block 12}

Below are several statements that you may agree or disagree with. Please indicate your level of agreement by selecting the appropriate, corresponding bubble on the scale below. Please be open and honest in your responding. 
When I make plans, I am certain I can make them work.
$\mathrm{O}$
0
0
O
O
O
O

One of my problems is that I cannot get down to work when I should.

If I can't do a job the first time, I keep trying until I can.

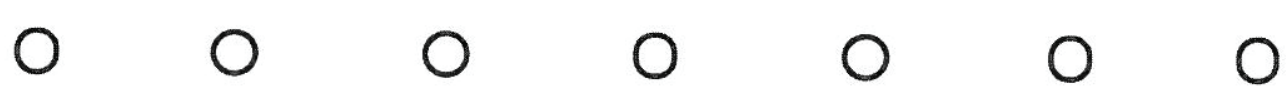

When I set important goals for myself, I rarely achieve them.

I give up on things before completing them.

\section{I avoid facing} difficulties.
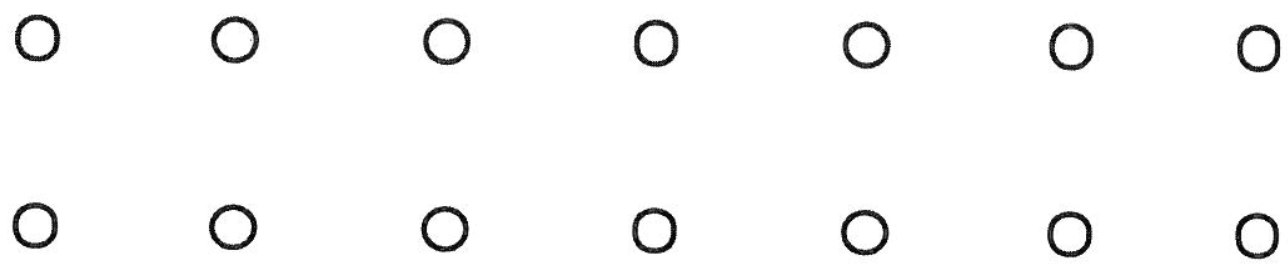

If something looks too complicated, I will not even bother to try it.

When I have something unpleasant to do, I stick to it until I finish it.

When I decide to do something, I go right to work on it.

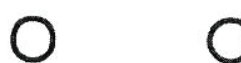

$\mathrm{O}$

O

0

0

$\mathrm{O}$

O

O

O

O

$\mathrm{O}$

O

0

O

0

O

O

$0 \quad 0$

0

O

O

$\mathrm{O}$

O

When trying to learn something new, I soon give up if I'm not initially successful.
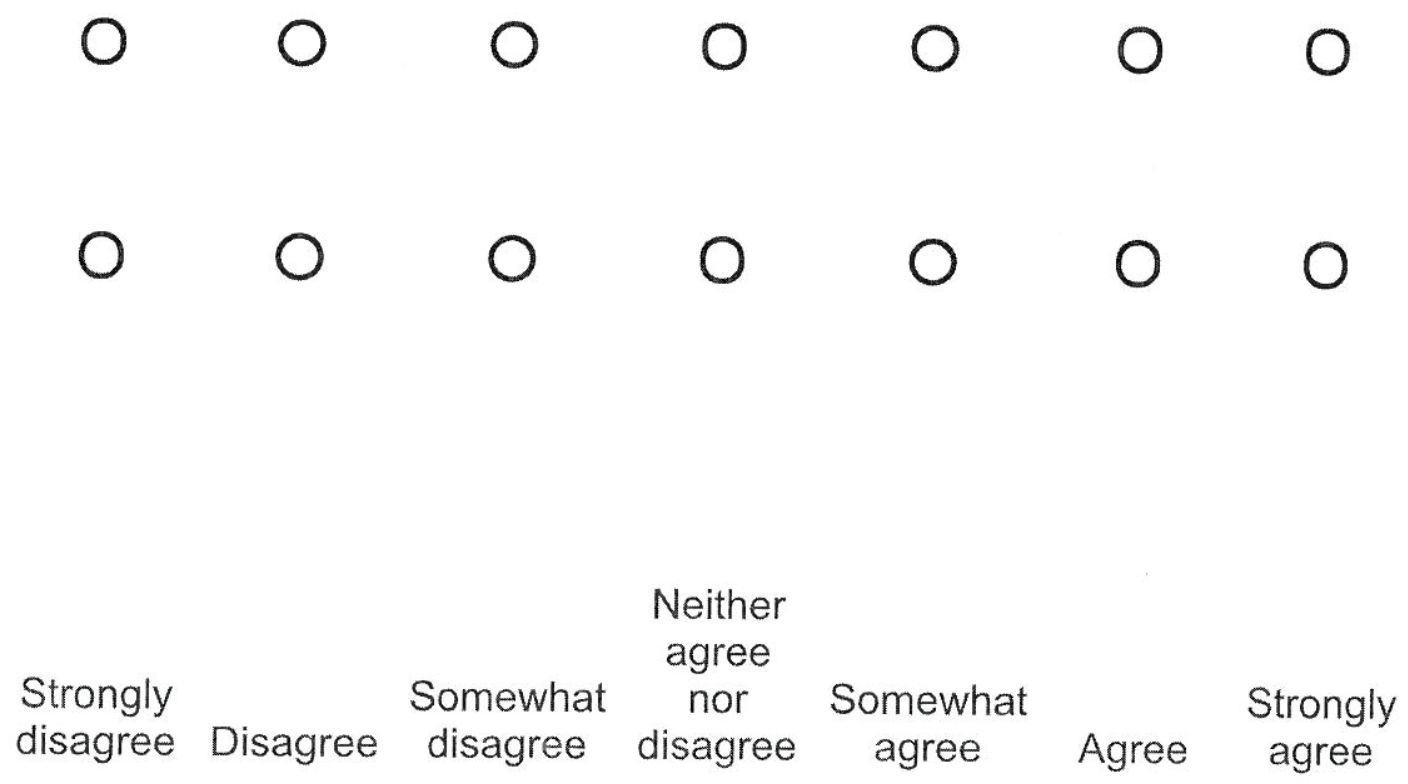

When unexpected 
propiems occur, I don't handle them

$0 \quad 0 \quad 0$

0

0

well.

I avoid trying to learn new things when they look too

$\begin{array}{llllllll}0 & 0 & 0 & 0 & 0 & 0\end{array}$

difficult for me.

Failure just makes me try harder.

$0 \quad 0 \quad 0$

00

0

I feel insecure about my ability to do things.

0

0

O

0

0

0

I am a self-reliant person.

O

I give up easily.

O

00

O 0

0

I do not seem

capable of dealing with most problems

000

0

0

0

that come up in life.

It is difficult for me to make new

friends.

If I see someone I would like to meet, I go to that person instead of waiting for him or her to

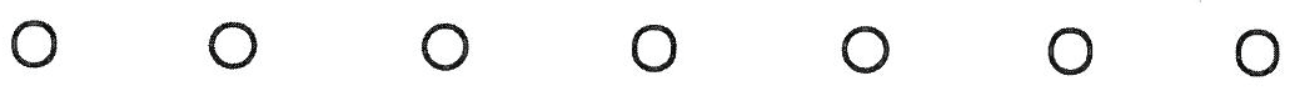
come to me.

If I meet someone interesting who is hard to make friends with, I'll soon stop trying to make friends with that person.

When I'm trying to become friends with someone who seems uninterested at first, I don't give up easily.
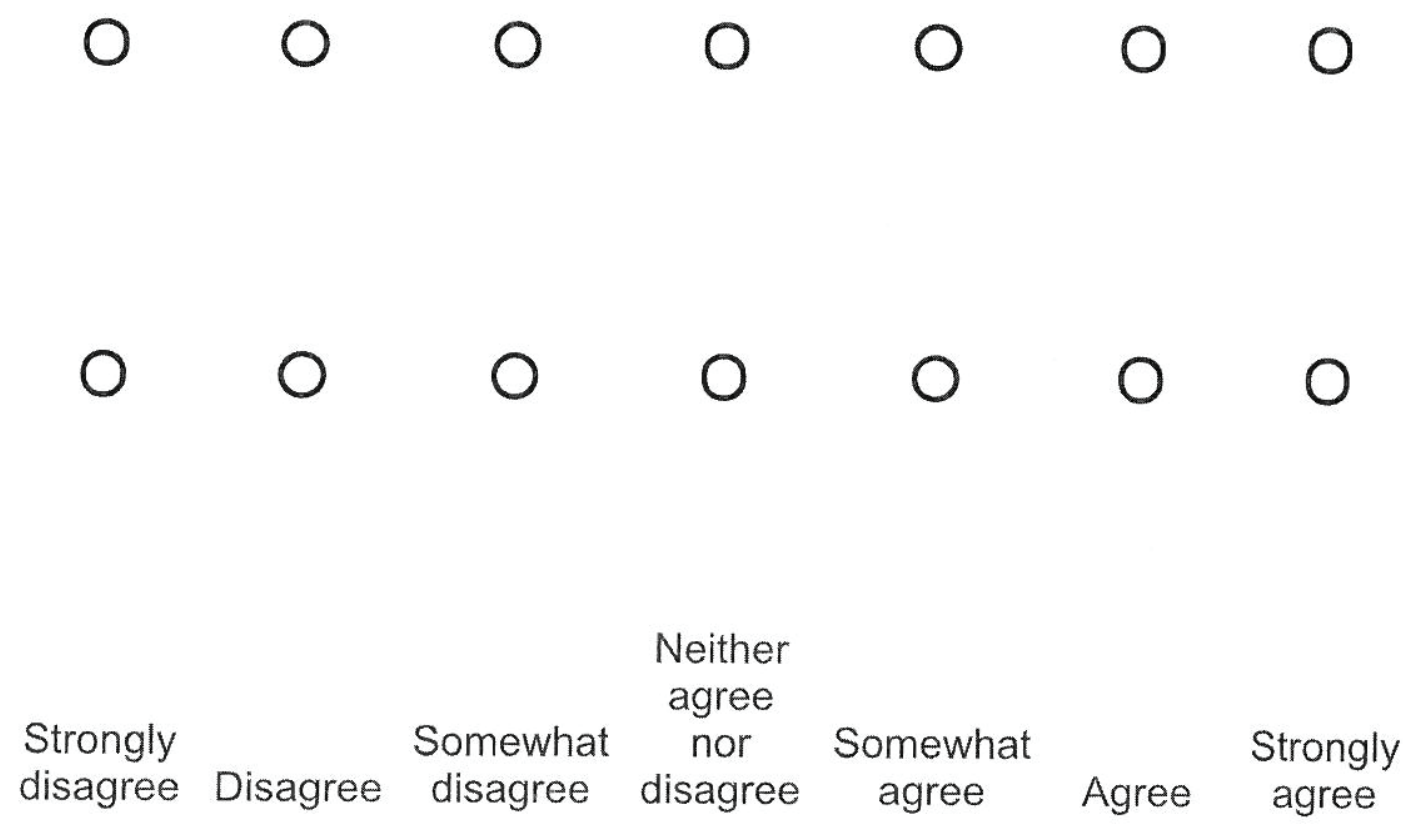

I do not handle 
I have acquired my friends through my personal abilities at making friends.

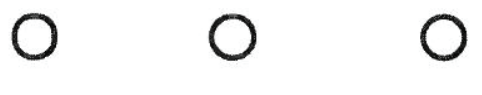

\section{Block 8}

Now we wish to learn more about YOU as the participant. Report on yourself for the questions on this page.

\section{Demographics}

I live:

in the United States.

outside of the United States.

I live in $a / n$ :

urban area.

rural area.

suburban area.

My age is:

\section{$\checkmark$}

My sex is:

Male

Female

Male to Female Transgender

Female to Male Transgender 
Nonbinary

Other

Among these choices, I most strongly identify as:

Asian / Asian American

Black / African American

Hispanic

Native American

White / Caucasian

Middle Eastern

Other

\section{Block 7}

We all vary in terms of how much we are who we want to be, both in terms of how we view ourselves and the way we present ourselves to other people.

We want you to think about your gender identity. How much are you who you want to be? How much are you who you want to be in your relationships with other people?

To/by yourself

What are you

"supposed to" perform

in your gender

identity?
Within your closest personal relationship With a boss/coworker

\section{To/by yourself}

Within your closest personal relationship With a boss/coworker

What/how do you actually perform your gender identity in this space?

What, if anything, would you want to change?
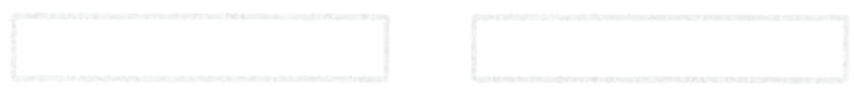

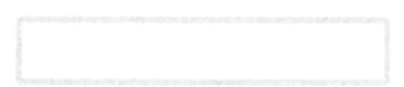


What satisfies you about what you said above?

What dissatisfies you about what you said above?

\section{Block 10}

Have you ever had a fatal heart attack?

Yes

No

The Earth has three moons. True or false?

True

False

Powered by Qualtrics 